\title{
Using morphometrics to reappraise old collections: The study case of the Congo Basin Middle Stone Age bifacial industry
}

\author{
Isis Mesfin $^{1}$, Alice Leplongeon ${ }^{1,2}$, David Pleurdeau ${ }^{1}$, Antony Borel ${ }^{1,3}$ \\ 1. UMR 7194 CNRS. Département Homme et Environnement, Muséum national d’Histoire naturelle - \\ Université Perpignan Via Domitia - Alliance Sorbonne Université, 1 rue René-Panhard, 75013 Paris, France. \\ Email: Mesfin: isis.mesfin@edu.mnhn.fr; Leplongeon: alice.leplongeon@gmail.com; \\ Pleurdeau: david.pleurdeau@mnhn.fr; Borel: antony.borel@mnhn.fr \\ 2. Institute of Advanced Study and Department of Cultural Heritage, Alma Mater Studiorum University of \\ Bologna, Bologna, Italy \\ 3. Institute of Archaeological Sciences, Eötvös Loránd University, Múzeum krt. 4/b, 1088 Budapest, Hungary.
}

\begin{abstract}
:
Despite its strategic location within the continent, Central Africa is rarely integrated into the reconstruction of population dynamics during the Middle Stone Age (MSA) of Africa, especially in terms of the emergence, diffusion and behavioural patterns of Homo sapiens. However, hundreds of sites have been discovered in Central Africa during the 20th century and attributed to the Lupemban, one of the main MSA technological complexes of the region. This complex is mainly characterised by typological criteria based on the numerous bifacial pieces found in the Congo Basin and interpreted as an adaption to the rainforest environment. Most of these Lupemban assemblages have not been studied for decades and thus it is particularly difficult to assess their diversity. This paper presents a detailed combined morphometrical approach (linear measurements and indices, Log Shape Ratio, Elliptic Fourier Analysis) to take a fresh and rigorous look at the Lupemban bifacial tools. We discuss the comparison of different morphometrical approaches to deal with "old" collections for which contexts, particularly chronological ones, are partially missing. We present the results of this approach on three assemblages of bifacial pieces gathered in the 1930s and late 1960s. We quantify their variability and discuss not only their homogeneity but also the variation of a Lupemban hallmark, namely the "Lupemban point".
\end{abstract}

Keywords: Lupemban; Congo Basin; bifacial points; Middle Stone Age; morphometrics; multivariate statistics; fossile directeur; hallmark; old collections

\section{Introduction}

In Africa, the Middle Stone Age (MSA) covers a large part of the Middle and Upper Pleistocene and is characterised by several technological innovations compared to the preceding Acheulean (Brooks et al. 2018; Douze 2011; McBrearty \& Brooks 2000; Pleurdeau 2003). These innovations seem to coincide with the emergence and diffusion of Homo sapiens

Published by the School of History, Classics and Archaeology, University of Edinburgh ISSN: 2055-0472. URL: http://journals.ed.ac.uk/lithicstudies/ 
(Clark et al., 2003; Hublin et al., 2017; White et al., 2003). In Central Africa, the first recorded lithic assemblages were collected in the Tumba lake area (Democratic Republic of Congo) and several prehistoric periods were described collectively as the Tumbakultur (Menghin 1925). Later on, to specify this chrono-cultural period, it was divided into two main complexes: the Sangoan (transitional complex from Earlier to Middle Stone Age) and Lupemban (Middle Stone Age complex). Around one hundred sites have been attributed to the Lupemban complex, which is mainly found in the Congo Basin (Clark 1967; Taylor 2016). These are generally considered as evidence of the first Homo sapiens settlement of the African rainforest (Taylor 2011). However, most of the sites have unclear, undescribed or disturbed stratigraphic contexts. All known Lupemban occurrences are open-air sites and lithic remains are located in alluvial deposits often disturbed by post-depositional processes, resulting in frequent vertical disturbance due to a phenomenon known as 'stone-lines' (Brown et al. 2004; Mercader et al. 2002; Schwartz 1996). So far, there are no known coherent or easily datable stratigraphic contexts in the Congo Basin for Lupemban occupations, although this may be due to research bias as very little recent fieldwork has taken place in the region.

The Lupemban is defined by numerous typologies based on shaped tools (Figure 1) (Breuil 1943; Leakey 1949; Matoumba 2013: 201; Pommeret 1965; Van Moorsel 1968) and has been interpreted as a "forest industry" and an adaptation to the African rainforest since its range encompasses the African equatorial belt (de Bayle des Hermens 1973; Bequaert \& Mortelmans 1955; Breuil 1933; Clark 1971; Matoumba 2011; Pommeret 1965).
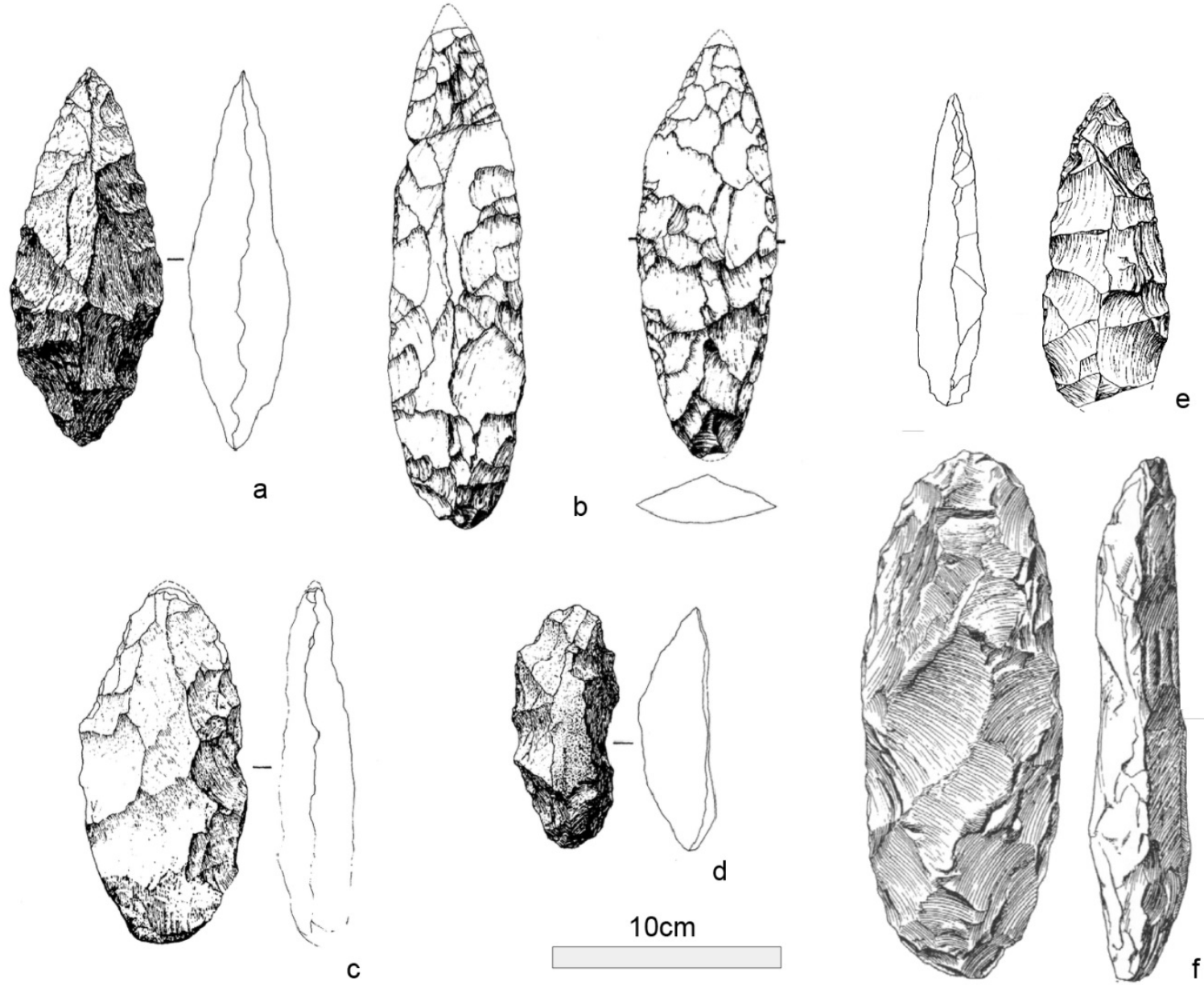

Figure 1. Examples of bifacial shaped tools attributed to Lupemban or Sangoan-Lupemban; a,b,c,d: from Muguruk (Kenya) (McBrearty 1985), e: from Mosumu (Equatorial Guinea) (Mercader 2002), f: from Nsongezi (Uganda) (O’Brien 1939). a, b and e are identified as Lupemban points. 
Typologically, the hallmark of the Lupemban is the "Lupemban point" or "Lupemban lanceolate”. It is defined as a bifacial lanceolate-shaped tool with a pointed distal extremity and sharp retouched edges, although the proximal part may adopt a diverse range of morphologies (de Bayle des Hermens 1973; Breuil 1943; Cornelissen 2002; Leakey 1949; Taylor 2009). The retouch may be carried out either by direct percussion or pressure flaking (Figure 1a, b, e). Few other technological criteria exist to define a Lupemban point and the global appreciation of a "lanceolate" shape (distal convergence of edges on an elongated blank) remains relatively subjective. The absence of quantitative data (for instance, elongation indices, minimal or maximal angle of edge convergence) in the existing literature hampers inter-assemblage comparisons. The definition of a Lupemban point thus remains very broad and can easily bring together a wide variety of shaped tools. However, the identification of this specific tool alone by researchers often results in the attribution of the whole assemblage to the Lupemban complex, which may also explain why Lupemban assemblages are characterised by a great diversity of heavy and light duty tools and a non-standardised flake production. Several authors add other characteristics such as the presence of backed tools at Kalambo Falls in Zambia (Barham 2002), grinding material and arrow heads at several sites from Congo Basin (Cornelissen 2002), and volumetric blade production at Sai Island in Sudan (Van Peer et al. 2004).

Most of the assemblages attributed to the Lupemban complex come from relatively old fieldworks. Recent detailed reviews of these assemblages provide a state of the art of the Lupemban, summarising its main issues including stratigraphic integrity of the sites, chronological range and available palaeoenvironmental data (Taylor 2009; 2011; 2016).

Only few Lupemban assemblages are dated and available ages suggest a large chronological hiatus questioning the definition and the homogeneity of this complex (Figure 2):

- In the Congo Basin, radiocarbon ages range from 40ka (Maboue V, Gabon) (Assoko Ndong 2002) to $12 \mathrm{ka}$ (Kinshasa Plain, Democratic Republic of Congo) (Van Moorsel 1968).

- In the southern margins of Central Africa, Uranium-Thorium dating has placed the earliest age for the Lupemban at 230ka at Twin Rivers (Zambia) (Barham \& Smart 1996).

- In the Nile Valley, OSL dating of the Lupemban layer from Sai Island (Sudan) produced an age of 182 $\pm 20 \mathrm{ka}$ (Van Peer et al. 2003).

- In the Lake Victoria area, the Sangoan-Lupemban assemblage of Muguruk (Kenya) has been estimated between 30 and 120ka based on sedimentation rates (McBrearty 1988).

Although the region is at the heart of the continent, the lack of reliable chronological and stratigraphic contexts for most Lupemban sites contributes to the exclusion of the region from the reconstruction of past population dynamics in Africa.

Since the main research expeditions in this region took place during colonial times, most of the stone tools are now stored in European museums and most of them have not been reappraised since their discovery (Couttenier 2012). Even though the archaeological field methods used at the time are not comparable to methods today, these old collections are rich in information as they are at the root of the original definition of the Lupemban complex. Therefore, when considered with careful evaluation of their biases, these collections represent an important body of data for reassessing the Lupemban complex and better understanding the Central African Middle Stone Age. 


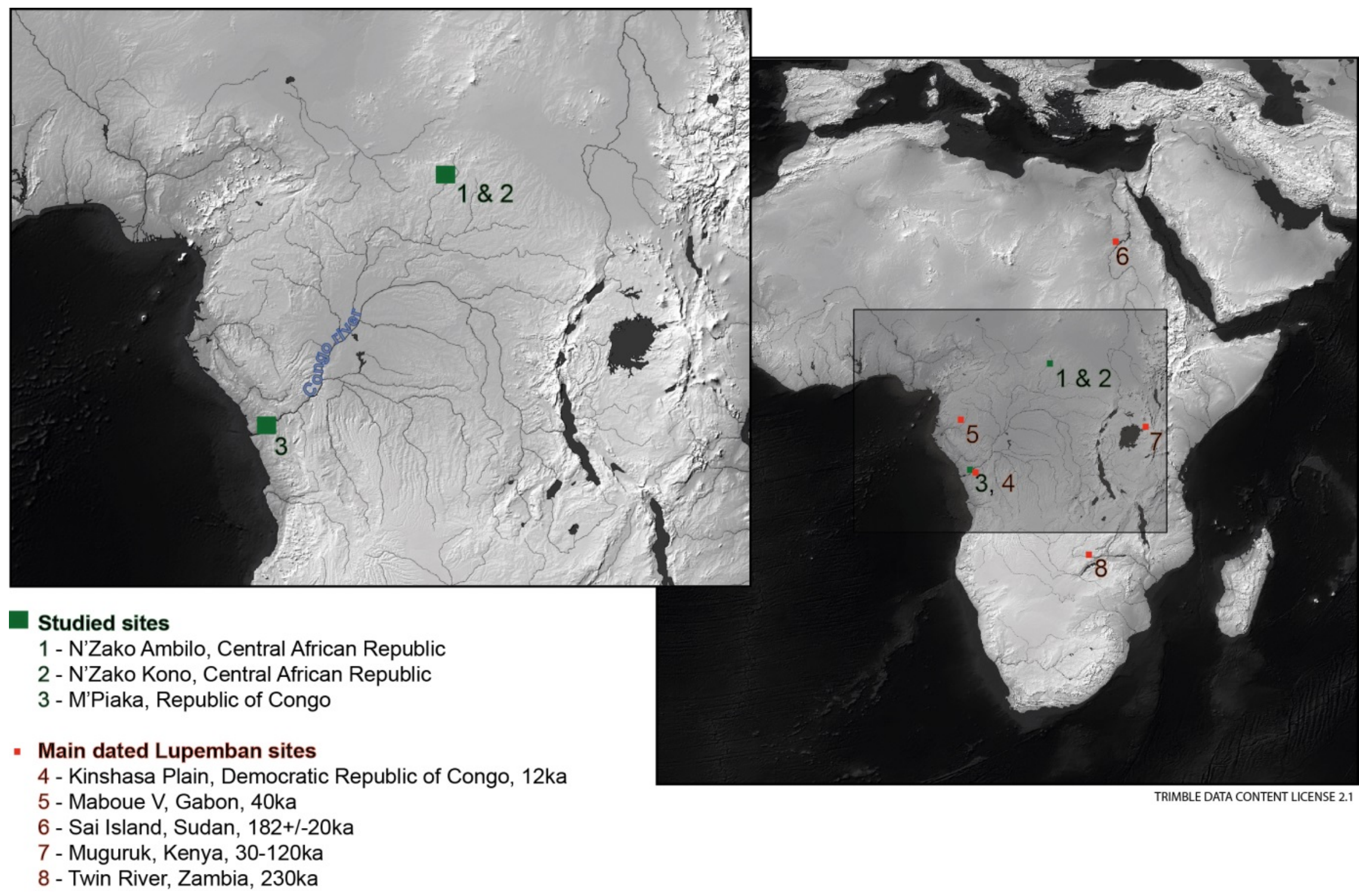

Figure 2. Map of the studied area and location of studied sites and main dated sites within the Congo Basin and its margins. 


\section{Objectives}

In past research, particularly during the middle of the 20th century, Central African sites have been discovered and attributed to the Lupemban complex based on typological criteria, the precise definition of which are often lacking (see above). Previous studies documented a high typological variability in Lupemban assemblages (Breuil 1943; Leakey 1949; Van Moorsel 1968; Clark 2001), and the lack of homogeneity among the assemblages has been highlighted through recent literature reviews (Taylor 2016). However, this variability has never been quantified using thorough comparative analyses.

In response to this, this paper aims to evaluate the variability of bifacial shaped tools within and between assemblages attributed to the Lupemban complex, using Central African collections from the Musée de l'Homme (French Muséum National d'Histoire naturelle (MNHN)) and from the Institut de Paléolontologie Humaine in Paris.

Lithic assemblages gathered at the beginning of the 20th century are often subject to a collection bias, with selection of retouched pieces at the expense of debitage products and small products $(<2 \mathrm{~cm})$. To overcome this bias, this study focuses only on shaped tools, which are less affected by the selection process, and therefore is particularly well-suited to the reassessment of 'old' collections. Previous studies have already highlighted the potential of morphometrics as an alternative to typology for assessing assemblages with partially missing chrono-stratigraphic contexts (Serwatka \& Riede 2016).

Relying on existing museum collections, we aim to:

- quantify the shape (conformation and size) variability of the Lupemban shaped tools usually used for regional typology.

- test the morphometric homogeneity of tools defined as "Lupemban points", an important hallmark of this complex.

- create a database with quantified data on Lupemban assemblages, allowing the use of data from Central African MSA lithic industries for future comparative studies.

\section{Materials}

Among the assemblages stored at the MNHN which historically contributed to the definition of the Lupemban, we selected the ones associated with documentation (archives, stratigraphic data, inventory, marking on pieces, etc.) and mentioned in the last updated inventory of Lupemban sites by N. Taylor (2016). This resulted in the selection of assemblages from three sites, all located in the Congo Basin (Figure 2): M'Piaka in Brazzaville (Republic of Congo), N'Zako Ambilo and N'Zako Kono (Central African Republic). These sites have been considered as "probable stone-line accumulation" (Taylor 2016); however, their discoverers argued for non-vertically disturbed sites. These are open-air sites and their material was found in buried deposits. They are not described as multi-period occupations and all the material collected has been attributed to the Lupemban only. The stratigraphic context of M'Piaka is described by G. Droux and G. Bergeaud (1937) who correlate the sequence they observe with the stratigraphy of the site of M'Pila, another site from Brazzaville. M'Pila is composed of three main stratigraphic units, the second of which ("argilliferous sands") is characterised by separate archaeological layers ( Demayumba 2018; Lanfranchi \& Lanfranchi-Salvi 1986). G. Droux and G. Bergeaud (1937) also indicate "in situ” material at M'Piaka in a very fresh state of conservation (Droux \& Bergeaud 1937). Concerning the N'Zako sites, R. de Bayle des Hermens did not observe any vertical disturbance of the deposits (i.e., stone-lines) but possible horizontal disturbance (de Bayle des Hermens 1973). Based on these characteristics, the three sites of this study are among the least disturbed sites known for the Lupemban complex in the Congo basin (e.g., filters 5 and 6 in Taylor, 2016). However, the absence of field notebooks and the lack of appropriate 
recording methods for the lithic material means that M'Piaka, N'Zako Ambilo and N'Zako Kono offer poorly contextualised assemblages where only layer attribution remains.

Among all of the shaped tools of these assemblages, we sampled only entire bifacially shaped tools and excluded uni- and trifacially ones and broken pieces. No roughouts have been identified in the corpus. Unifacially and trifacially shaped tools have been excluded because these products suggest another strategy of volume management or a very low reduction of the blank. This resulted in a sample of 156 bifacially shaped pieces. Further publications (Mesfin 2018; Mesfin et al. in prep.) detail the technological analysis and allow a more holistic view of these lithic assemblages in their entirety (core, flakes and shaped tools) (Figure 3).

Bifacial tools from the three assemblages are characterised by homogeneity in the shaping process (Figure 4) with:

- integral or marginal shaping which completely modifies the original shape of the blank.

- when identifiable, mainly large flakes $(>10 \mathrm{~cm})$ used as blanks.

- diversity of the area affected by the retouch, suggesting an important control of the final shape (regularisation or diversity of active parts). Most of the bifacial shaped tools reached the stage of retouching (75\% in N'Zako Ambilo, 75\% in N'Zako Kono and 77.5\% in M'Piaka).

Among these assemblages, we identified "Lupemban lanceolate points" ( $n=31)$ based on the definition presented in the introduction: bifacial shaping, convergent distal edges, lateral retouch, and rectilinear lateral edges (Figure 5). No morphometrically precise definition exists for these products. Despite a broad definition, these points are not so numerous among the Lupemban shaped tools assemblage (20\%).

\subsection{N'Zako Ambilo (NZA), Mbomou Prefecture, Central African Republic}

Ninety-two bifacially shaped tools (53.9\% of the whole assemblage) out of a total of 136 shaped tools have been selected from the assemblages of N'Zako Ambilo (NZA) and were gathered by R. de Bayle des Hermens in 1967 on the bedrock of diamondiferous alluvial deposits of the N'Zako River in north-eastern Central African Republic (north of the Congo water system) (de Bayle des Hermens 1973). Only 18.5\% $(n=17)$ of the selected bifacial tools match the Lupemban point definition.

\subsection{N’Zako Kono (NZK), Mbomou Prefecture, Central African Republic}

Thirty-five (44.3\% of the whole assemblage) out of 58 shaped tools from N'Zako Kono (NZK) have been bifacially shaped and were therefore selected for the present study. Among them, $25.7 \%(n=9)$ match the Lupemban point definition. This assemblage was also gathered by R. de Bayle des Hermens in 1967 and 1968, a few kilometres upstream of N'Zako Ambilo (de Bayle des Hermens 1973). Both sites share the same stratigraphic context.

\subsection{M'Piaka (MP), Brazzaville Department, Republic of Congo}

M'Piaka (MP) is part of a set of sites discovered in Brazzaville during the 1930s, a period of construction and development of the town (Droux \& Bergeaud 1937). It is located around the Pool Malebo, an area rich in prehistoric settlements since the Acheulean (Babet 1936; Lanfranchi \& Lanfranchi-Salvi 1986; Lanfranchi-Salvi 1990). There are 29 bifacial shaped tools (28.7\% of the whole assemblage) out of a total of 64 shaped tools gathered in two unspecified localities nearby. Among this sample, $16.7 \%(n=5)$ match the Lupemban point definition. The whole assemblage possesses a very good and homogeneous state of preservation, with all ridges and edges fresh. 


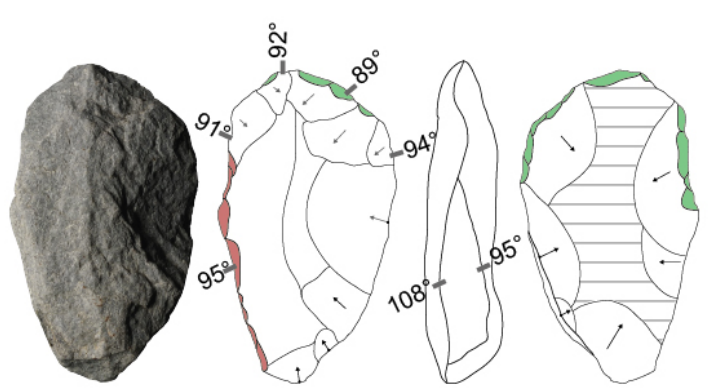

NZA97 - Partialy bifacially shaped tool on flake. The distal part is larger with a robust cutting edge, and two natural lateral flats suggest prehensive parts. One of the of lateral flats is retouched to be regularised.

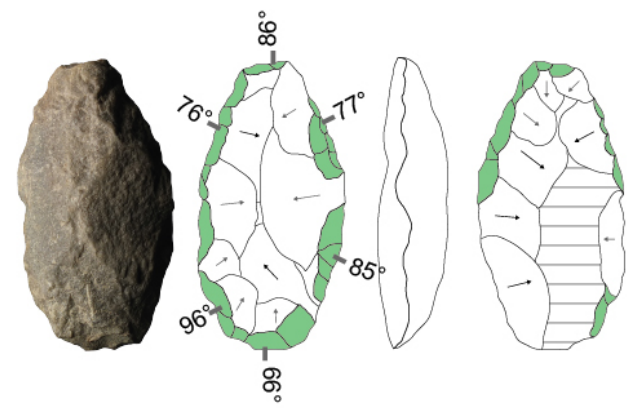

NZK124 - Partialy bifacially shaped tool on flake. The retouch covers the whole edges and indicates different possible active parts (lateral, proximal and distal) with peripherical robust cutting edges.
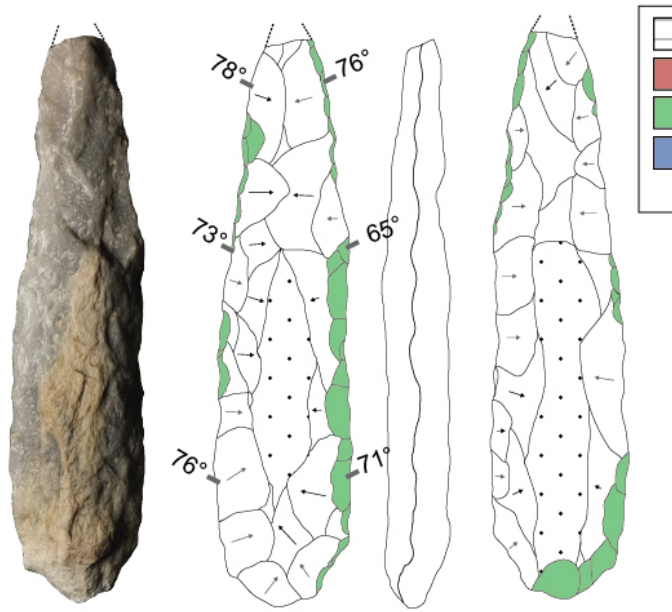

NZA21 - Partialy bifacially shaped tool on slab. The knapper used the natural blank to produce a long and thin shaped tool. The distalpart is broken but the overall morphology suggest a possible pointed tip. flake's inferior face retouch of the pointed tip potential retouched active part

1st removals generation 2nd removals generation potential retouched prehensive part - impact point - $5 \mathrm{~cm}$
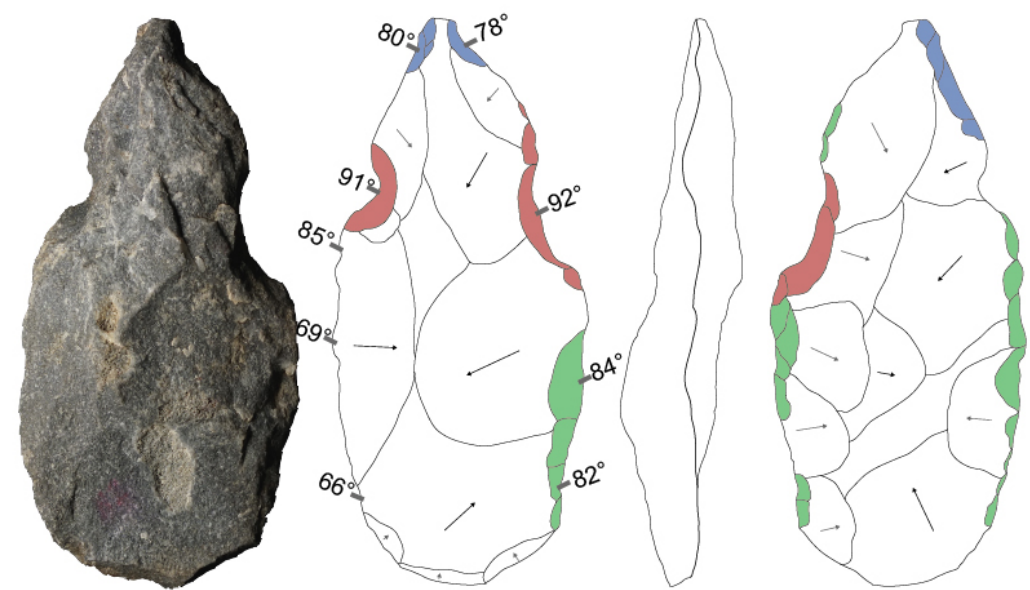

NZA26 - Entirely bifacially shaped tool. Different retouched areas indicate different functional parts. Two lateral distal notches made with several removals indicate a possible prehenive/hafted part and design the specific morphology of the tool. The ventral unifacial retouch of the lateral right part offers a thin cutting edge opposed to a robust bifacialy retouched one.

Figure 3. Example of diacritical schemes from bifacially shaped tools from N'Zako Ambilo and N'Zako Kono. 

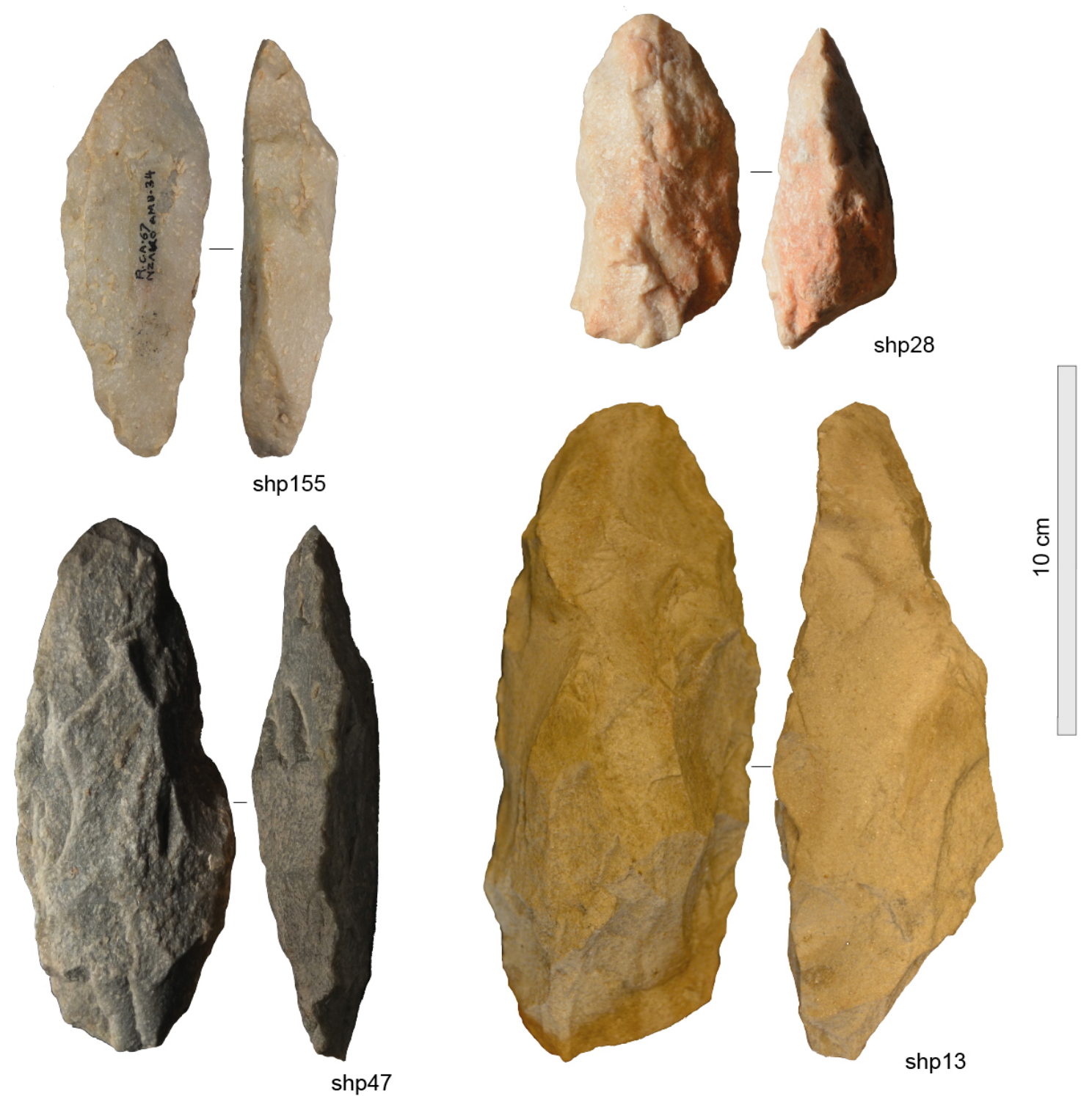

Figure 4. Example of bifacial shaped tools from assemblages, shp155: N’Zako Ambilo (NZA), shp28 \& shp13: M’Piaka (MP), shp47: N’Zako Kono (NZK). 

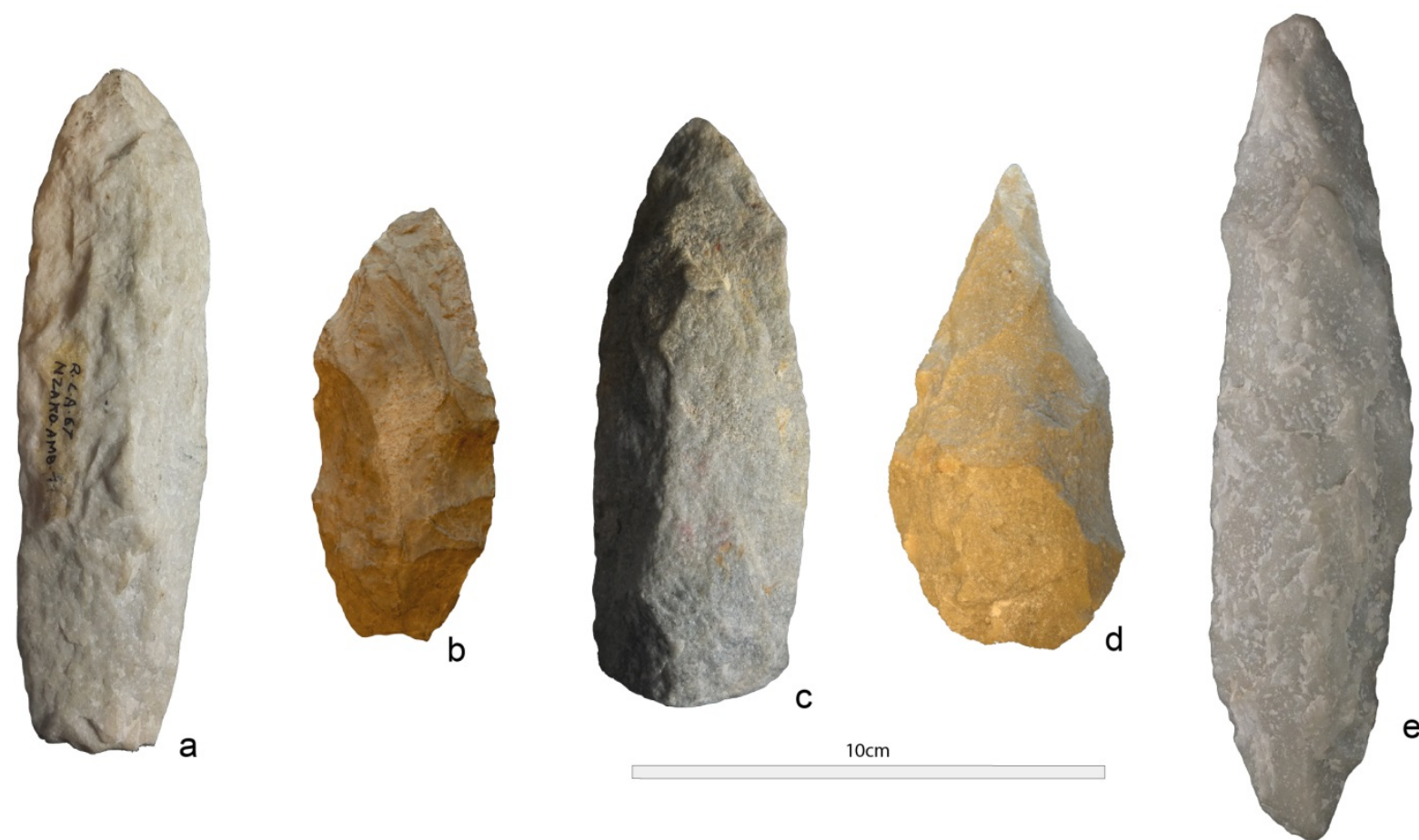

Figure 5. Examples of shaped pieces which matched the Lupemban point criteria. a, e: N'Zako Ambilo (NZA), b: M’Piaka (MP), c: N’Zako Kono (NZK), d: M’Piaka (MP).

There are a number of logistical factors (for example, diamond mines, construction work, time spent in the field and field storage conditions) that likely explain the selection process applied by R. de Bayle des Hermens, G. Droux and G. Bergeaud at the time of collection, leading to the preferential representation of shaped tools in these assemblages. Despite poor stratigraphic descriptions which limit the resolution of chronological and spatial data, these sites have not been described as vertically disturbed and thus are an important body of data to understand the Lupemban in the Congo Basin, particularly in the absence of other well-dated sites with well-defined stratigraphic contexts in the Congo Basin (Taylor 2016). However, the lack of more precise stratigraphic contexts for these collections still requires us to consider these assemblages cautiously.

\section{Methods}

Our main objective in this study is to quantify morphometric variability of Lupemban shaped tools and to test Lupemban Complex homogeneity or diversity using only bifacial pieces. Additionally, we aim to propose an example of using combined morphometric approaches on shaped tools. To do this, we used traditional morphometrics (based on linear measurements, including metric data of the profiles to obtain Log Shape Ratio (LSR) and five indices) and geometric morphometrics (based on 2D outlines using Elliptical Fourier Analysis). We applied these methods firstly to the whole assemblage of bifacial shaped tools, and then we focused on the Lupemban points only.

In the present study, we did not use the same typology as the one published by the discoverers of the site (de Bayle des Hermens 1973; Droux \& Bergeaud 1937) and as such, it was not always possible to correlate between their attributions and ours. Furthermore, the material they published does not always correspond to the whole assemblages they collected. As a result, our inventory of artefacts differs from theirs. 


\subsection{Traditional morphometrics and Log Shape Ratio (LSR)}

Both methods (traditional morphometrics based on five indices and LSR) use linear measurements, providing an approximation of the proportions of the pieces in plane and profile views. In order to highlight patterns of variability among the selected assemblages, we first calculated five indices (Table 1) based on the proximal, distal and maximum width and thickness, and the length (Figure 6). Raw linear measurements are presented in supplementary materials.

Table 1. The five morphometric indices and their interpretation.

\begin{tabular}{lll}
\hline & Ratio & Interpretation \\
\hline Elongation index & Length:max. width & Elongated piece $>$ broad piece \\
Fineness index 1 & Length:max. thickness & Thin piece $>$ thick piece \\
Fineness index 2 & Width:max. thickness & Thin piece $>$ thick piece \\
Distal robustness index & Distal width:distal thickness & $\begin{array}{l}\text { Gracile extremity }>\text { robust } \\
\text { extremity }\end{array}$ \\
Proximal robustness & Proximal width:proximal & Gracile extremity $>$ robust \\
index & thickness & extremity \\
\hline
\end{tabular}

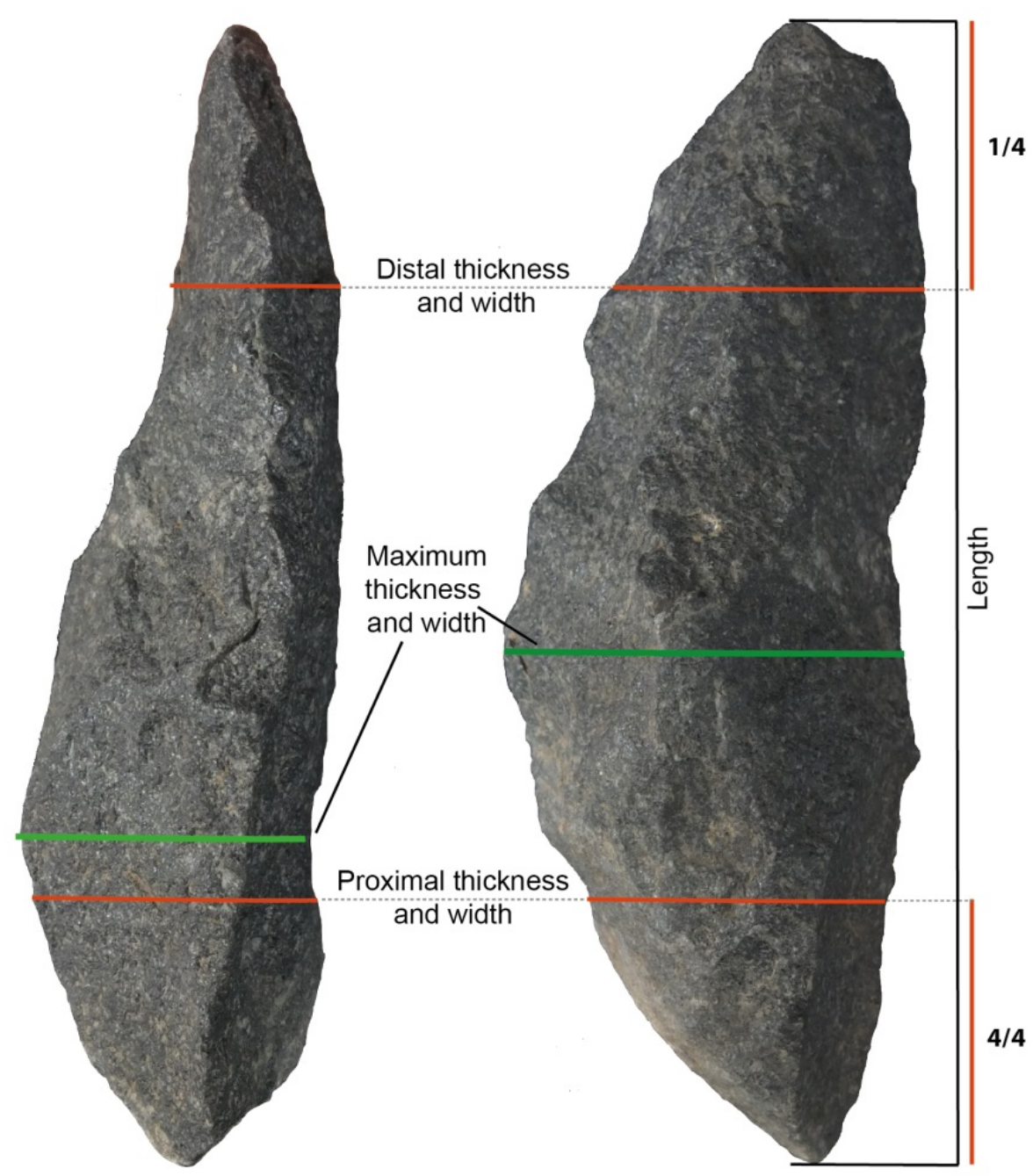

Figure 6. Description of the linear measurements on a piece from N'Zako Ambilo (NZA). Distal thickness and width have been measured at $1 / 4$ of the length from the distal end, and proximal thickness and width at the $3 / 4$ of the length from the distal end. 
The LSR method (Mosimann 1970) was used to deconstruct the form into its components of size (here, isometric size) and shape in order to examine shape variation among the assemblages. The isometric size is the natural logarithm of the geometric mean of the measurements of a stone artefact (i.e., length, width and thickness). The shape ratio of a measurement is calculated by dividing the value of this measurement by the geometric mean of the measurements of the artefacts. The LSR is the natural logarithm of the shape ratio (e.g., Borel et al. 2017). LSR allows us to investigate size and shape effects and variation separately but since it is based on linear measurements, it does not consider the irregularities of the outlines of the artefacts so additional geometric morphometric methods are required.

\subsection{Geometric morphometrics}

Both methods detailed above do not account for the complexity of the shape of the artefacts. To quantify these shapes and their variability we applied Elliptical Fourier Analysis (EFA) on 2D outlines. A further advantage of EFA over LSR is the ability to visualise the shape variations. Recent research has applied both 2D and 3D EFA to lithic artefacts in different contexts (Borel 2012; Borel et al. 2017; Cardillo 2010; Chacón et al. 2016; Ioviţă 2009; Ioviţă \& McPherron 2011; Okumura \& Araujo 2018; Rezek et al. 2011; Serwatka 2015). This approach avoids empirical and often subjective descriptors such as "rectangular", "triangular" and "round" that can hamper objective comparisons of assemblages.

The 156 complete bifacial pieces sampled were photographed using a Fujifilm X10 camera for NZA and NZK and Nikon D5200 for MP. Pieces were placed on the inferior face (the flattest) and oriented according to their technological axis next to a $10 \mathrm{~cm}$ scale. Then each outline was calibrated and scaled before being extracted clockwise with the semiautomatic mode in TPSDig2.31 (Rohlf 2015; 2018). We placed 100 equidistant semilandmarks from one main landmark placed on the distal extremity (the maximal curve on the round extremity) (Figure 7).

The coordinates of the points on the outlines (Figure 8a) were processed with R (R Core Team 2018) using Momocs package (Bonhomme 2012; Bonhomme et al. 2014). Procrustes superimposition was applied to normalise the outlines: the centroid of each outline was translated to the same coordinates $(0,0)$, outlines were scaled and rotated to minimise the summed squared distances between the points along each outline and the average position of these points within the sample (Figure 8b). Then, EFA allowed us to decompose the outlines in a set of harmonics (the higher the number of harmonics, the higher the details of the reconstructed shape). Ten harmonics representing 99\% of the original shape were kept for this analysis. Each harmonic is composed of four coefficients, giving a total of 40 coefficients by described shape.

The centroid size of each outline (the square root of the sum of squared distances between each point on the outline and their centroid (Bookstein 1997)) was also computed in order to investigate shape variation depending on size among the assemblages. Size is an important attribute of stone tools which may largely influence tool-use. 


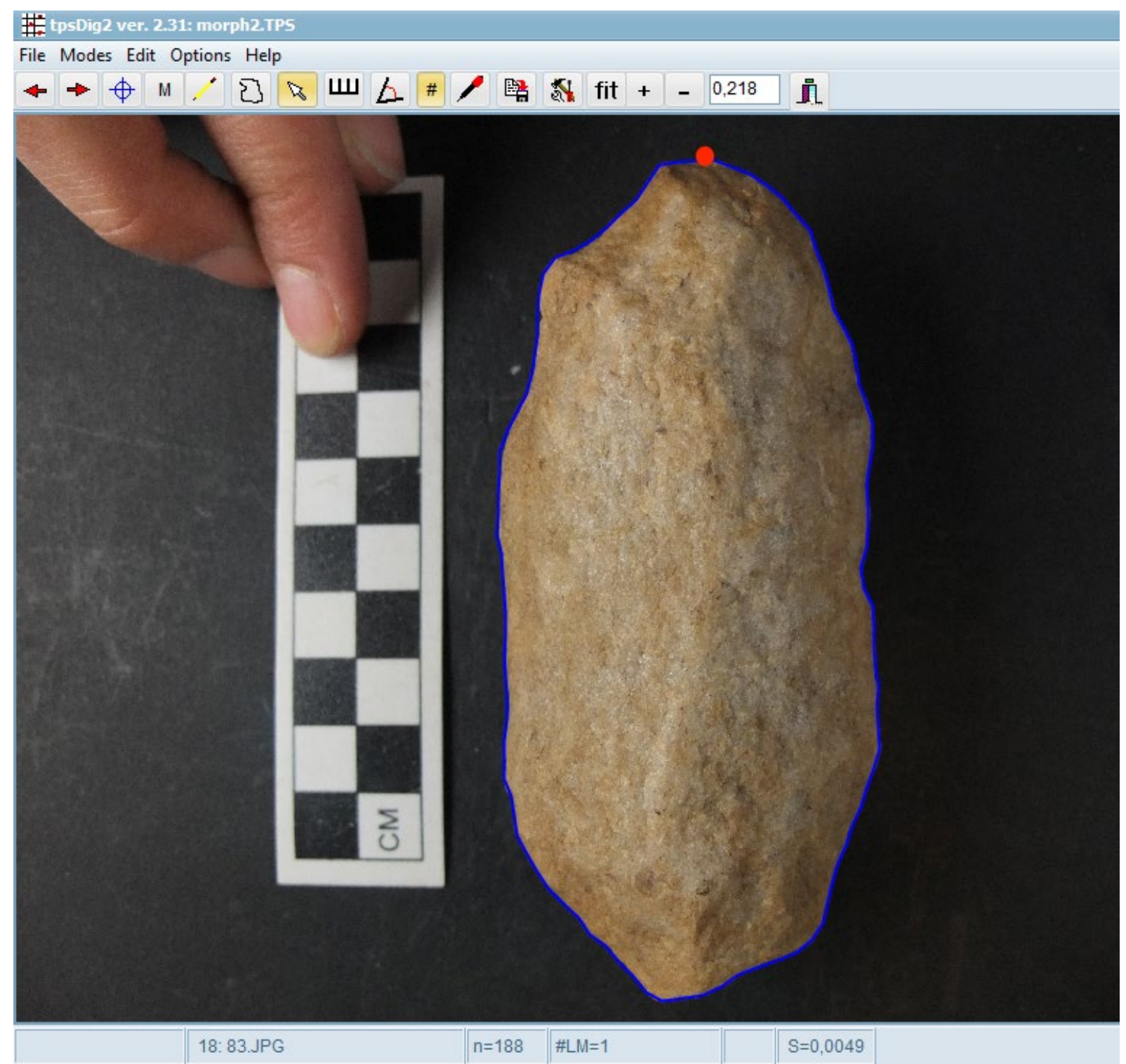

Figure 7. Example of outline extraction using TPSDig2.31. 


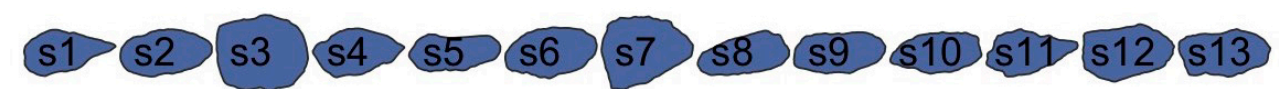

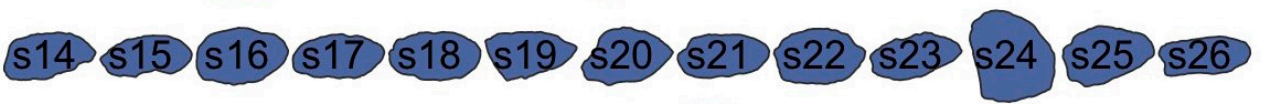

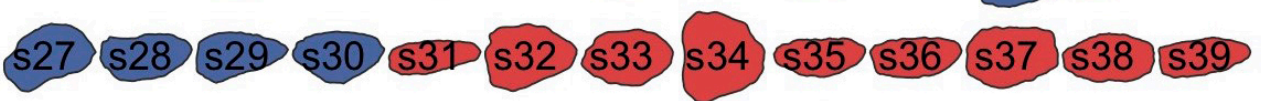
$\$ 40$ \$41 \$42 \$43 \$44\$ \$45 \$46 \$47 \$48 \$49 \$50 \$51 \$52

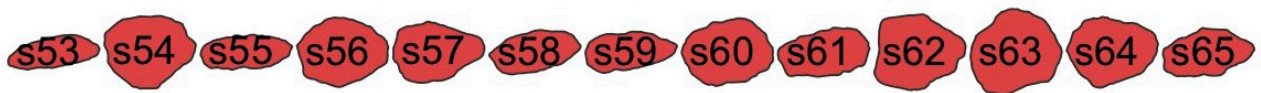

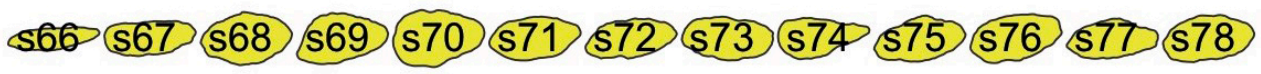

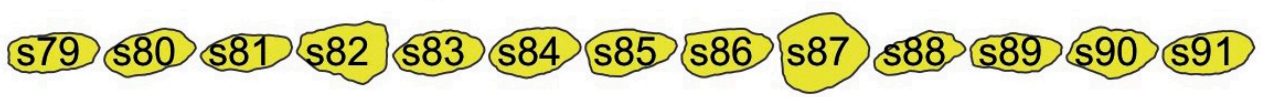

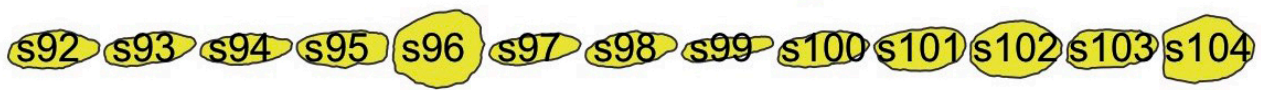
$\$ 105 \$ 106 \$ 107 \$ 108 \$ 109 \$ 110 \$ 111 \$ 112 \$ 113 \$ 114 \$ 115 \$ 110 \$ 117$ $\$ 118 \$ 119 \$ 120 \$ 127 \$ 122 \$ 123 \$ 124 \$ 125 \$ 126 \$ 127 \$ 128 \$ 129 \$ 130$

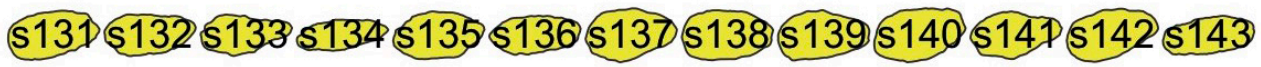
\$144) $\$ 145 \$ 140 \$ 147 \$ 148 \$ 149 \$ 150 \$ 151 \$ 152 \$ 153 \$ 154 \$ 155 \$ 150$ 5157 $\square$ M'Piaka $\square$ N'Zako Kono $\square$ N'Zako Ambilo

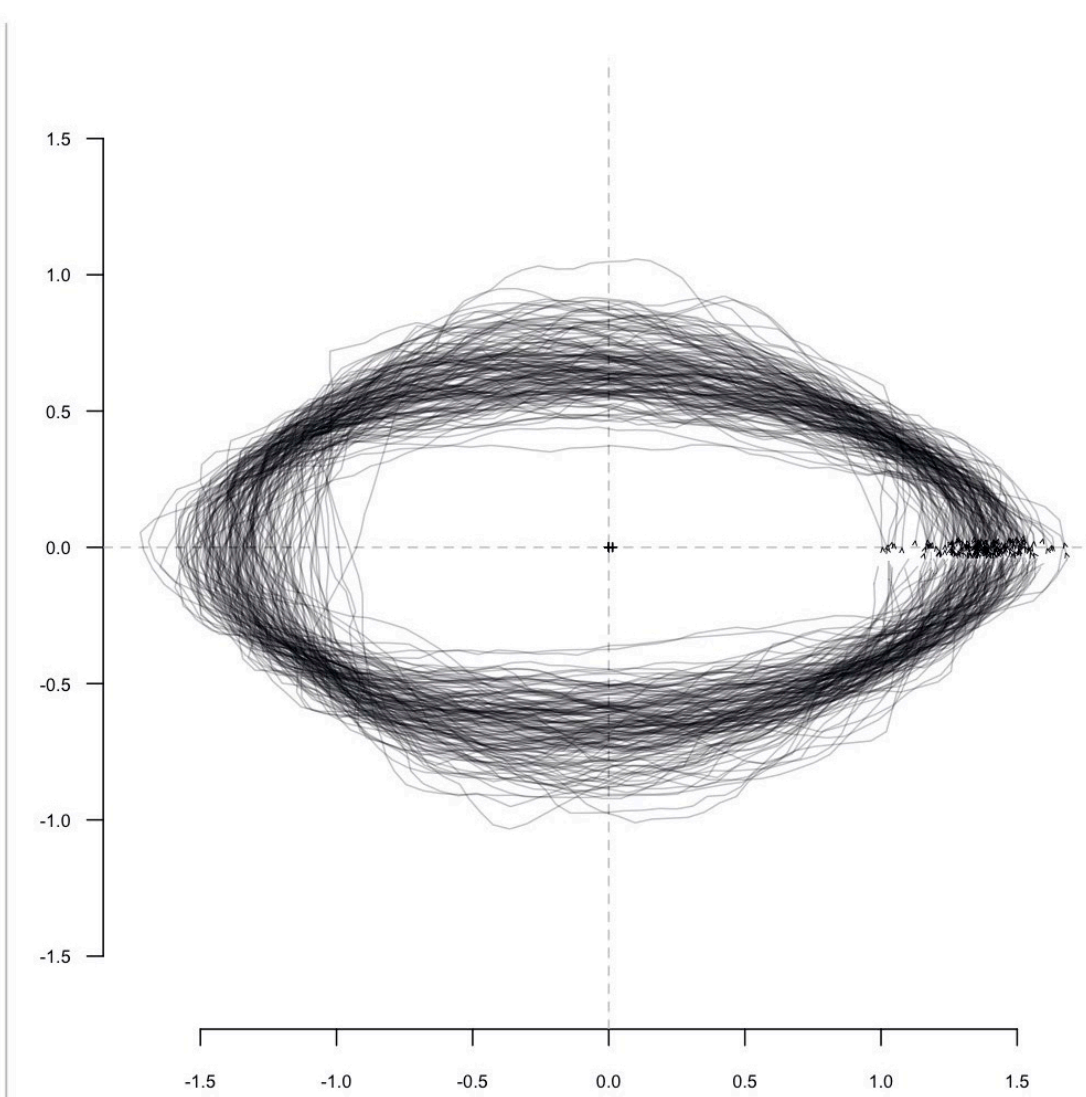

Figure 8. a: Panel of all extracted outlines (blue: MP, red: NZK, yellow: NZA). b: Result of the normalisation of outlines using Procrustes superimposition. Pieces are aligned along the $\mathrm{x}$-axis. 


\subsection{Data statistical treatment}

The five indices, the LSR and the EFA coefficients were all examined with Principal Component Analysis (PCA). The FactoMineR package (Husson et al. 2018; Lê et al. 2008) in $\mathrm{R}$ (R Core Team 2018) was used for PCA visualisation and mapping of the qualitative data. For each data set, we applied PCA on the whole assemblage and then on Lupemban points only (Table 2). Centroid size versus shape was also visualised to investigate whether particular shapes are related to the size of the artefacts. Multivariate Analysis of Variance (MANOVA) was performed on the five indices based on linear measurements, Principal Components (PCs) scores from EFA coefficients and PCs scores from LSR data set versus qualitative variables. Qualitative variables were tested to verify if artefacts show significant differences in shape depending on their site of origin (NZA, NZK, MP), their raw material (sandstone, quartzite, sandstone-quartzite, quartz, silicified limestone, chert), the symmetry of their section (symmetrical or asymmetrical) and their type (point or other) (Table 3). The Pillai Trace test was used as the size of our sample is uneven from one site to another (Carlson 2017). An alpha of 5\% was used for each statistical test. We also applied post-hoc Tukey Honestly Significant Difference (HSD) tests when the MANOVA indicated a p-value $<0.05$ to assess the differences. The p-values are automatically adjusted with the $\mathrm{R}$ function “TukeyHSD”.

Table 2. Summary of the data sets (quantitative variables and qualitative supplementary variables) used for the seven PCAs realised in this paper. The crosses indicate the data sets used and the qualitative variables added. PC1 to PC4 include the whole assemblage. PC5 to PC7 include the Lupemban points only.

\begin{tabular}{lccccccc}
\hline & PCA 1 & PCA 2 & PCA 3 & PCA 4 & PCA 5 & PCA 6 & PCA 7 \\
\hline Quantitative variables & & & & & & & \\
\hline $\begin{array}{l}\text { Fourier coeff. } \\
\text { LSR }\end{array}$ & & $X$ & $X$ & $X$ & & & $X$ \\
Five indices & $X$ & & & & $X$ & & \\
\hline $\begin{array}{l}\text { Qualitative supplementary } \\
\text { variables }\end{array}$ & & & & & & & \\
\hline Sites & $\mathrm{X}$ & $\mathrm{X}$ & $\mathrm{X}$ & & $\mathrm{X}$ & $\mathrm{X}$ & $\mathrm{X}$ \\
Raw material & $\mathrm{X}$ & $\mathrm{X}$ & $\mathrm{X}$ & & $\mathrm{X}$ & $\mathrm{X}$ & $\mathrm{X}$ \\
Section type & $\mathrm{X}$ & $\mathrm{X}$ & $\mathrm{X}$ & & $\mathrm{X}$ & $\mathrm{X}$ & $\mathrm{X}$ \\
Lupemban points & $\mathrm{X}$ & $\mathrm{X}$ & $\mathrm{X}$ & $\mathrm{X}$ & & & \\
\hline
\end{tabular}

Table 3. Summary of the data used (dependent variables and independent variables) in the MANOVAs.

\begin{tabular}{lcccc}
\hline Versus & Sites & Raw material & Section & Lupemban points \\
\hline PCA1 data set & $\mathrm{X}$ & $\mathrm{X}$ & $\mathrm{X}$ & $\mathrm{X}$ \\
PCA2 scores (PC1-2) & $\mathrm{X}$ & $\mathrm{X}$ & $\mathrm{X}$ & $\mathrm{X}$ \\
PCA3 scores (PC1-13) & $\mathrm{X}$ & $\mathrm{X}$ & $\mathrm{X}$ & $\mathrm{X}$ \\
PCA4 scores & & & & \\
PCA5 data set & $\mathrm{X}$ & $\mathrm{X}$ & $\mathrm{X}$ & \\
PCA6 scores (PC1-2) & $\mathrm{X}$ & $\mathrm{X}$ & $\mathrm{X}$ & \\
PCA7 scores (PC1-13) & $\mathrm{X}$ & $\mathrm{X}$ & $\mathrm{X}$ & \\
\hline
\end{tabular}




\section{Results}

\subsection{Metric data set}

Boxplots of the five ratios (Figure 9) show major differences between MP and the two N'Zako localities. In particular, the values for the elongation index and fineness index 1 are more homogeneous in MP than in the two other sites. However, the medians appear relatively similar between the three sites. We applied ANOVAs to test each index versus site separately and we obtained significant results for two indices: fineness index 1 (p-value: 0.0001145 ) and proximal robustness index (p-value: 0.005935). This indicates that these two variables, corresponding to measurements related to the profiles of the pieces, are the ones revealing differences between sites.

\section{Entire assemblages}

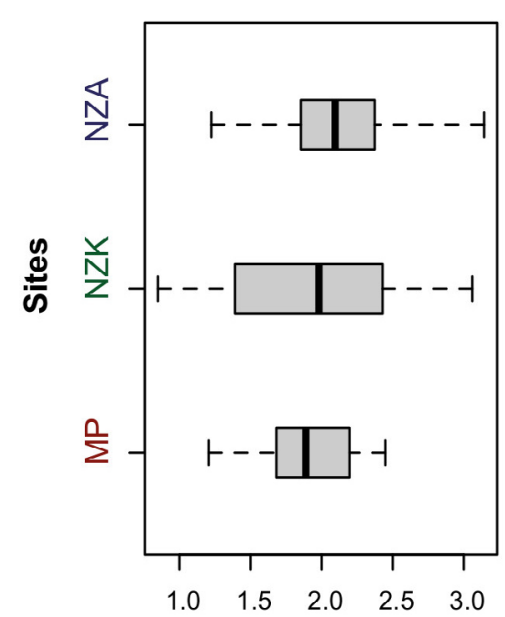

Elongation index

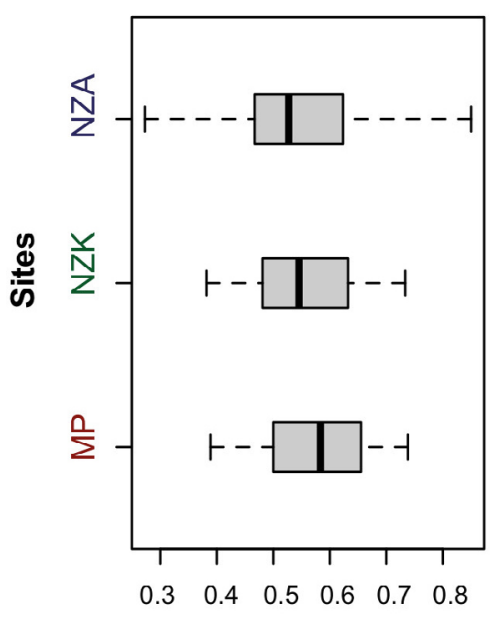

Distal robustness index

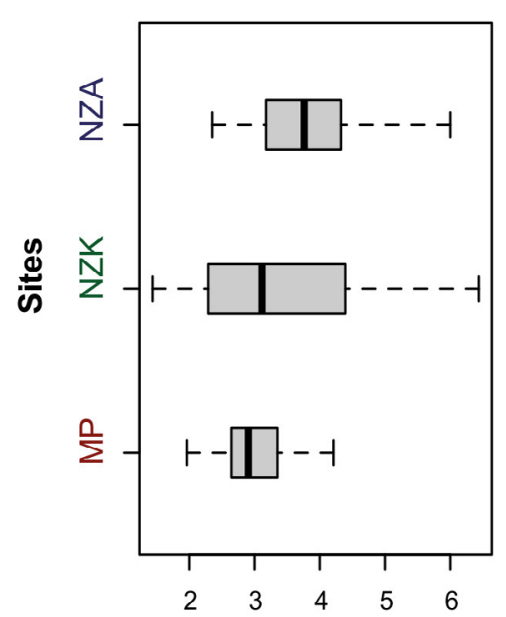

Fineness index 1

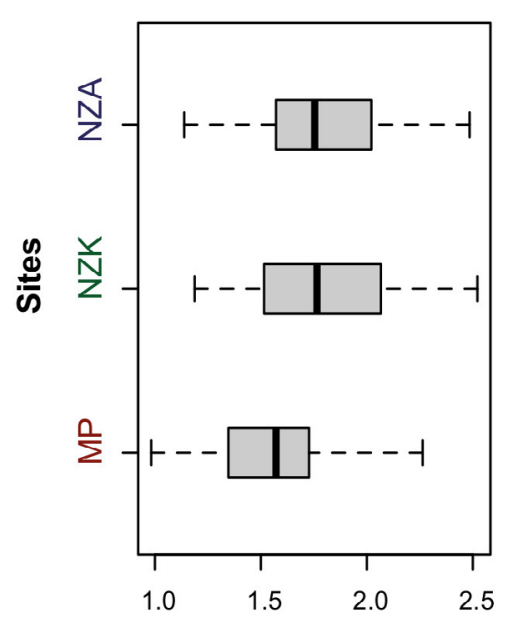

Fineness index 2

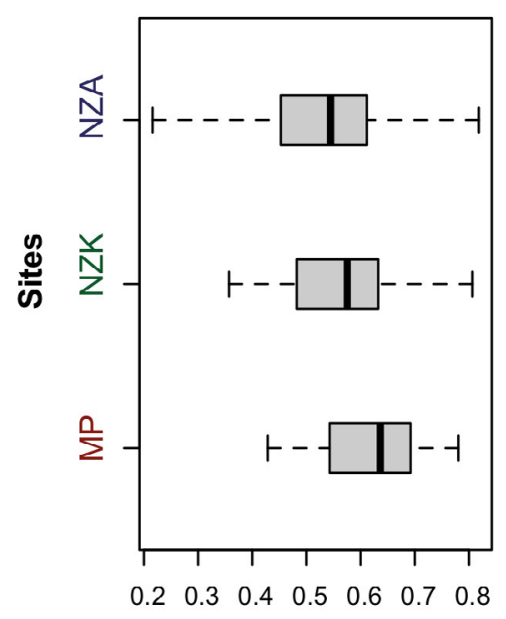

Proximal robustness index

Figure 9. Boxplots for indices and sites, integrating the whole bifacial shaped tools assemblages. (Elongation index: NZA $\bar{X}=2.149$, sd $=0.4568131$, NZK $\bar{X}=1.9488$, sd $=0.6461972$, MP $\bar{X}=1.892$, sd $=0.3660371$, Fineness index 1: NZA $\bar{X}=3.889, \mathrm{sd}=1.026811$, NZK $\bar{X}=3.476, \mathrm{sd}=1.349903$, MP $\bar{X}=2.897, \mathrm{sd}=0.7903313$, Fineness index 2: NZA $\bar{X}=1.834$, sd $=0.4131022$, NZK $\bar{X}=1.784, \mathrm{sd}=0.3571434$, MP $\overline{\mathrm{X}}=1.6379$, $\mathrm{sd}=0.3556337$, Distal robustness index: NZA $\bar{X}=0.5540$, $s d=0.1667991$, NZK $\bar{X}=0.5540$, sd $=0.1120987, \quad \mathrm{MP} \quad \overline{\mathrm{X}}=0.5926$, $\mathrm{sd}=0.1361706$, Proximal robustness index: NZA $\bar{X}=0.5410, \mathrm{sd}=0.1436929, \mathrm{NZK} \overline{\mathrm{X}}=0.5679, \mathrm{sd}=0.1166138, \mathrm{MP}$ $\overline{\mathrm{X}}=0.6268, \mathrm{sd}=0.1121678$ ) 
When considering Lupemban points only (Figure 10), we can observe a similar pattern of differences but in addition, the medians for the Lupemban points of MP are very different than for the other sites. NZA presents the most scattered dataset for all indices, followed by NZK. This suggests important differences in the metric proportions of stone points between the assemblages. We applied post-hoc Tukey HSD tests on each of the five indices. Results indicate that fineness index 1 and elongation are the two variables significantly differentiating sites, with the three other variables producing p-values $>0.05$ (Table 4). The morphology of Lupemban points from MP are statistically different from the ones from NZA and NZK. These two sites (NZA and NZK) do not present significant morphometric differences among their stone points assemblages.

\section{Lupemban points}

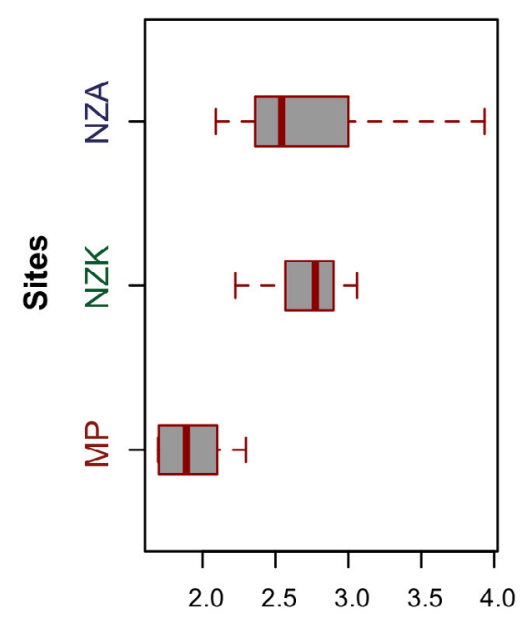

Elongation index

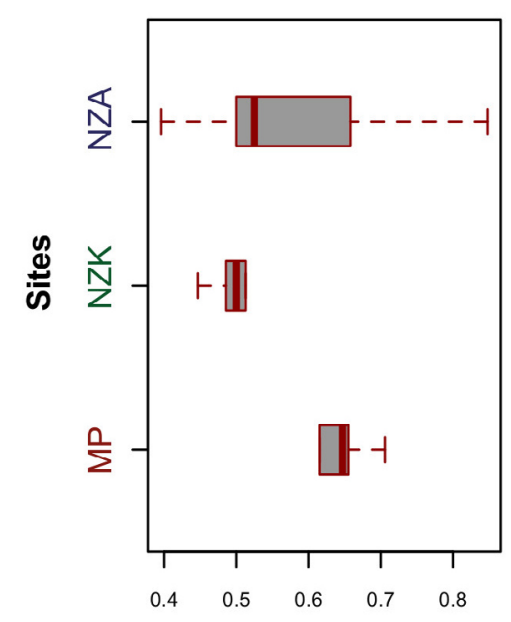

Distal robustness index

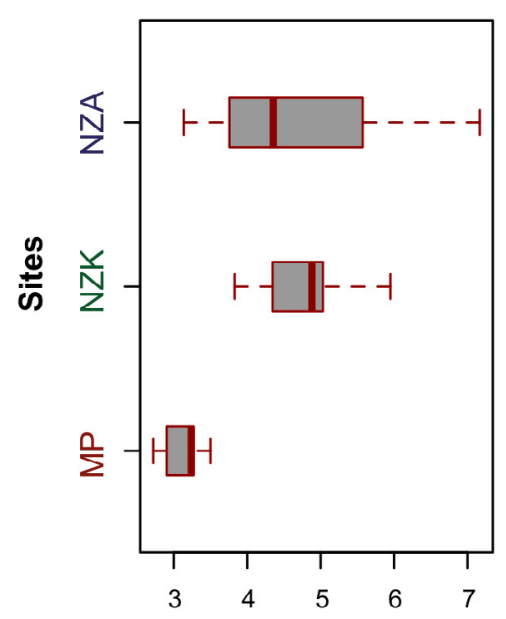

Fineness index 1

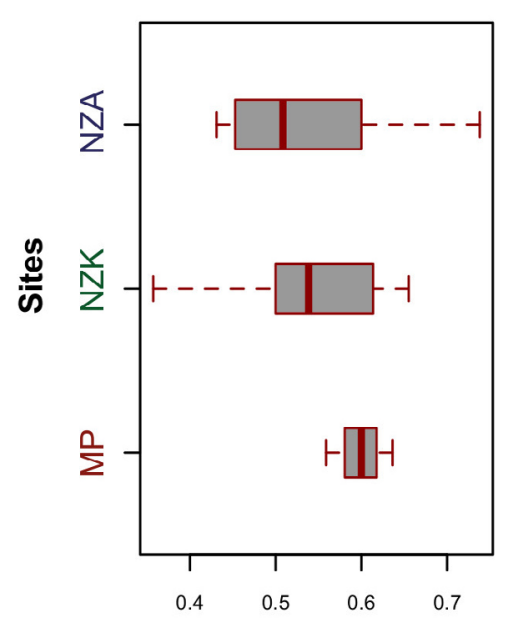

Proximal robustness index

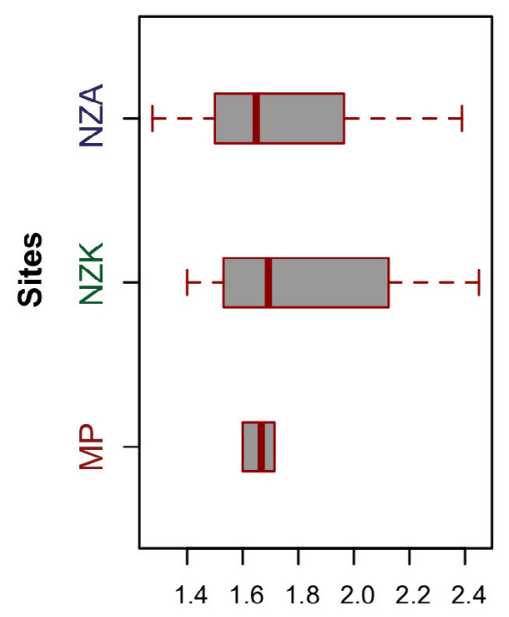

Fineness index 2

Figure 10. Boxplots for indices and sites, integrating the Lupemban points only. (Elongation indice: NZA $\bar{X}=2.696, \mathrm{sd}=0.4636399, \mathrm{NZK} \overline{\mathrm{X}}=2.726, \mathrm{sd}=0.2755363, \mathrm{MP} \overline{\mathrm{X}}=1.936, \mathrm{sd}=0.2615799$, Fineness index 1 : NZA $\bar{X}=4.750, \mathrm{sd}=1.268371, \mathrm{NZK} \overline{\mathrm{X}}=4.895, \mathrm{sd}=0.8399489, \mathrm{MP} \overline{\mathrm{X}}=3.126, \mathrm{sd}=0.3109412$, Fineness index 2 : NZA $\overline{\mathrm{X}}=1.755, \mathrm{sd}=0.3252214, \mathrm{NZK} \overline{\mathrm{X}}=1.813, \mathrm{sd}=0.3661243, \mathrm{MP} \overline{\mathrm{X}}=1.624, \mathrm{sd}=0.1215206$, Distal robustness index: NZA $\bar{X}=0.5765, \mathrm{sd}=0.07690242, \mathrm{NZK} \overline{\mathrm{X}}=0.5135, \mathrm{sd}=0.0790596, \mathrm{MP} \overline{\mathrm{X}}=0.6247, \mathrm{sd}=0.07690242$, Proximal robustness index: NZA $\overline{\mathrm{X}}=0.5501, \quad \mathrm{sd}=0.1242465, \quad \mathrm{NZK} \quad \overline{\mathrm{X}}=0.5284, \quad \mathrm{sd}=0.1050943, \quad \mathrm{MP} \quad \overline{\mathrm{X}}=0.5987$, $\mathrm{sd}=0.03039466)$ 
Table 4. Results of the post-hoc Tukey HSD tests conducted on fineness index 1 and elongation index for the Lupemban point assemblages. The significant values are in bold. diff. : difference in the observed means, lwr : lower end point of the interval, upr : upper end point of the interval, p-value adj : p-value after adjustment for the multiple comparisons.

\begin{tabular}{lllll}
\hline & Diff. & Lwr & Upr & p-value adj. \\
\hline Fineness index 1 versus sites & & & & \\
\hline NZK-MP & 1.7686297 & 0.2984987 & 3.2387606 & 0.0158969 \\
NZA-MP & 1.6233491 & 0.2824375 & 2.9642607 & 0.0151992 \\
NZK-NZA & -0.1452805 & -1.2318043 & 0.9412432 & 0.941572 \\
\hline Elongation index versus sites & & & & \\
\hline NZK-MP & 0.78950318 & 0.2473720 & 1.3316344 & 0.0033446 \\
NZA-MP & 0.76032708 & 0.2658473 & 1.2548068 & 0.0019839 \\
NZK-NZA & -0.02917611 & -0.4298468 & 0.3714946 & 0.9822734 \\
\hline
\end{tabular}

\subsection{Inter- and intra-site variability and the position of Lupemban points}

The PCA realised on the fineness, robustness and elongation indices (Table 5) shows that the first PC is mainly characterised by fineness indices 1 and 2 and the proximal robustness index (Figure 11). They mainly refer to measurements linked to the profile of the pieces and separate relatively thinner pieces with a gracile proximal extremity (negative values on PC1) from thicker pieces with a robust proximal extremity (positive values on PC1). The thinnest pieces are from NZA and are quite rare in other assemblages. PC2 opposes elongated pieces with gracile distal extremity to less elongated pieces with robust distal extremity. The variability of the Lupemban points on the first two PCs is included in the variability of the rest of the bifacial pieces (Figure 11a). On the contrary, several artefacts stand apart from the other bifacial pieces on the third PC (Figure 11b). This is particularly true for the points from NZA and NZK. The third PC, summarising more than $12 \%$ of the total variance, is characterised by fineness index 1 and opposes relatively thin profile products (positive values) to shorter and thicker profile products (negative values).

Table 5. Coordinates of the first four PCs and their $\cos ^{2}$ from the PCA1 presented in Figure 11. Variables with highest contribution and quality of representation on the PCs are shown in bold.

\begin{tabular}{|c|c|c|c|c|c|c|c|c|}
\hline & $\begin{array}{l}\text { Cos. }^{2} \\
\text { PC1 }\end{array}$ & $\begin{array}{l}\text { Coord. } \\
\text { PC1 }\end{array}$ & $\begin{array}{l}\text { Cos. }^{2} \\
\text { PC2 }\end{array}$ & $\begin{array}{l}\text { Coord. } \\
\text { PC2 }\end{array}$ & $\begin{array}{l}\text { Cos. }^{2} \\
\text { PC3 }\end{array}$ & $\begin{array}{l}\text { Coord. } \\
\text { PC3 }\end{array}$ & $\begin{array}{l}\text { Cos. }^{2} \\
\text { PC4 }\end{array}$ & $\begin{array}{l}\text { Coord. } \\
\text { PC4 }\end{array}$ \\
\hline $\begin{array}{l}\text { Fineness index } \\
2\end{array}$ & 0.81045 & -0.9002 & 0.00859 & 0.0926 & 0.00429 & -0.0655 & 0.17666 & 0.4203 \\
\hline $\begin{array}{l}\text { Distal } \\
\text { robustness } \\
\text { index }\end{array}$ & 0.33612 & 0.5797 & 0.59058 & -0.7684 & 0.04537 & 0.2130 & 0.02736 & 0.1654 \\
\hline $\begin{array}{l}\text { Proximal } \\
\text { robustness } \\
\text { index }\end{array}$ & 0.83047 & 0.9113 & 0.04096 & 0.2023 & 0.08706 & 0.2950 & 0.04081 & 0.2020 \\
\hline Elongation & 0.15410 & 0.3926 & 0.83085 & 0.9115 & 0.01142 & 0.1068 & 0.00291 & 0.0540 \\
\hline $\begin{array}{l}\text { Fineness index } \\
1\end{array}$ & 0.52112 & -0.7218 & 0.00034 & 0.6834 & 0.46714 & 0.6834 & 0.01143 & -0.1069 \\
\hline
\end{tabular}




\section{PCA1}

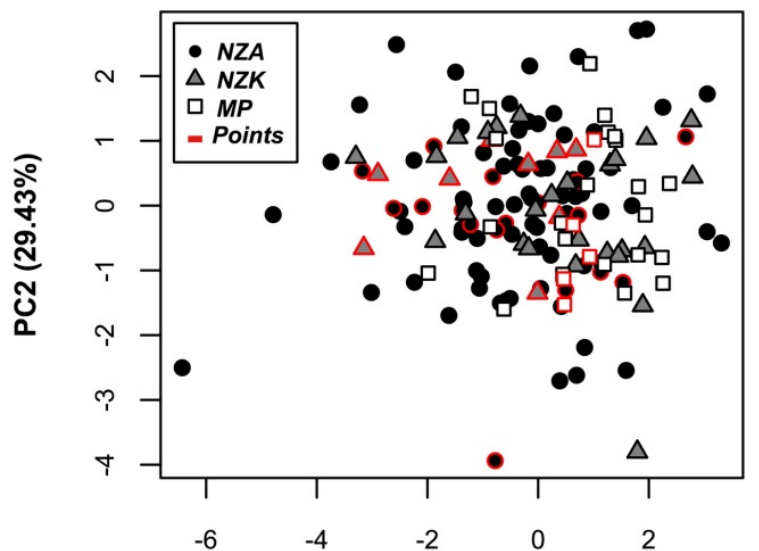

PC1 (53.05\%)

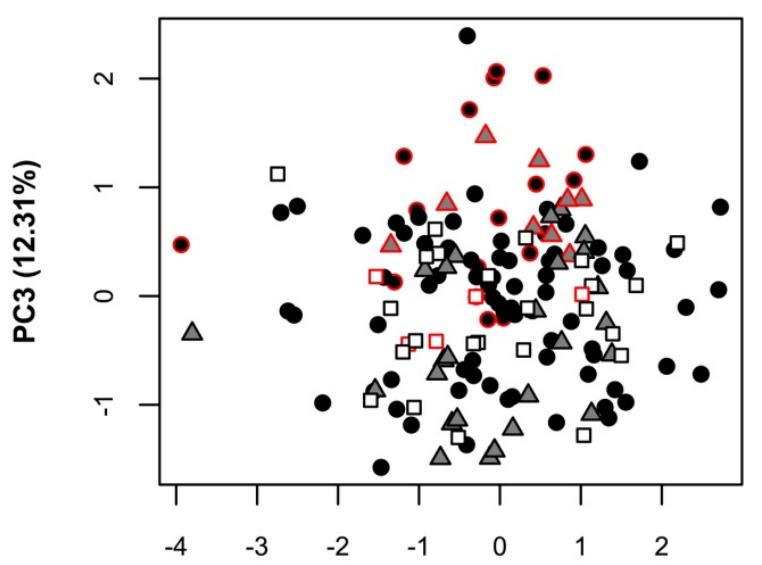

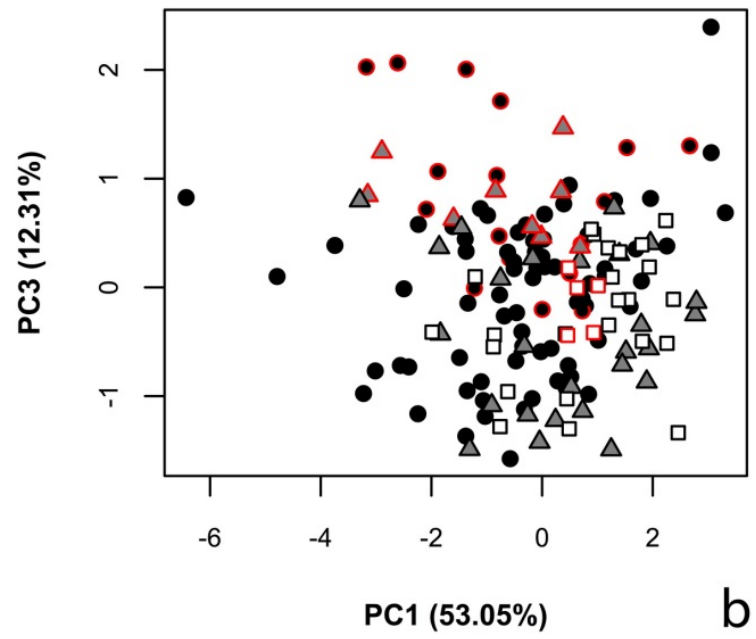

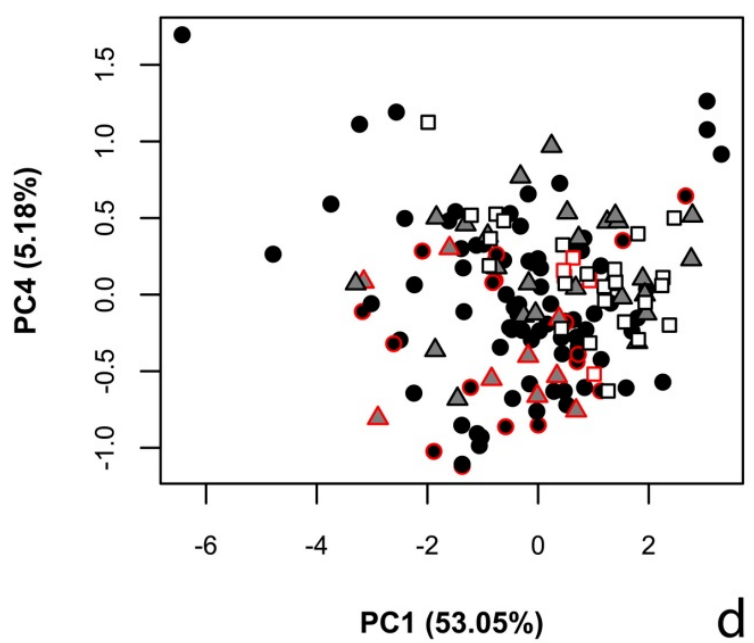

Figure 11. PCA1 - Plot of the scores of the first four PCs of the PCA realised on the five indices (fineness, robustness and elongation indices (see Table 1)). The results for this PCA are in Table 5. Symbols represent different sites (circles: NZA, triangles: NZK, squares: MP) and red outlines indicate Lupemban points.

The PCA realised on LSR is presented in Figure 12. The two first PCs gather $100 \%$ of variance. There does not seem to be any obvious pattern that would allow us to distinguish the bifacially shaped tools of one site from another. We notice the importance of the LSR-length (Table 6) on the first PC and this pattern is the one which distinguishes Lupemban points of NZA and NZK from their respective bifacially shaped tool assemblages. LSR-thickness is also well represented. This converges with the results of PCA1 on morphometric indices (Figure 11, Table 5).

Table 6. Coordinates of the two PCs and their $\cos ^{2}$ from the PCA2 presented in Figure 12. Variables with highest contribution and quality of representation on the PCs are shown in bold.

\begin{tabular}{lllll}
\hline & Cos2 PC1 & Coord. PC1 & Cos2 PC2 & Coord. PC2 \\
\hline LSR-length & 0.9922 & -0.9961 & 0.0077 & -0.0878 \\
LSR-width & 0.2017 & 0.4491 & 0.7982 & 0.8934 \\
LSR-thickness & 0.6051 & 0.7779 & 0.3948 & -0.6283 \\
\hline
\end{tabular}




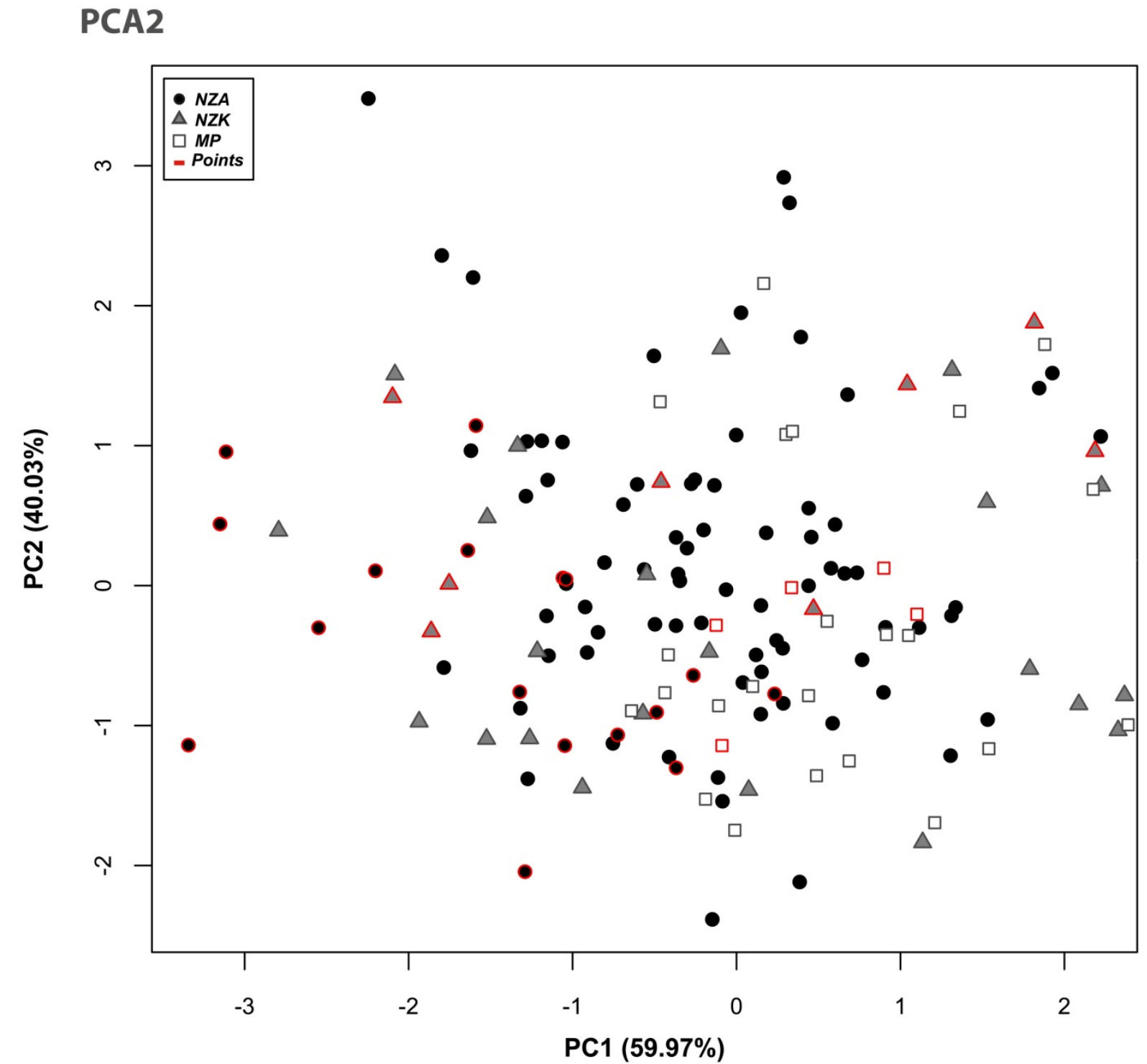

Figure 12. PCA2 - Plot of the PCA scores of the two PCs. PCA is realised on the three LSR variables. The results for this PCA are in Table 6 and concern the whole assemblages. Symbols represent sites (circles: NZA, triangles: NZK, squares: MP) and red outlines indicate points.

Based on the EFA coefficients, PCA3 (Figure 13) gave a similar distribution of the pieces to that of PCA1 and PCA2 (Figures 11 and 12). On the first four PCs, sites show almost complete overlap. The first PC is characterised by elongation. MP has fewer elongated products (negative values on PC1) than NZK and NZA. We can also observe that the products from NZA include two very elongated pieces and two very stocky pieces from NZK (Figure 13a). With the exception of these pieces, both sites share a very close range of variability. On the second PC, NZK presents the less extended distribution suggesting that longitudinal symmetry is more important for these pieces (Figure 13a, c). 


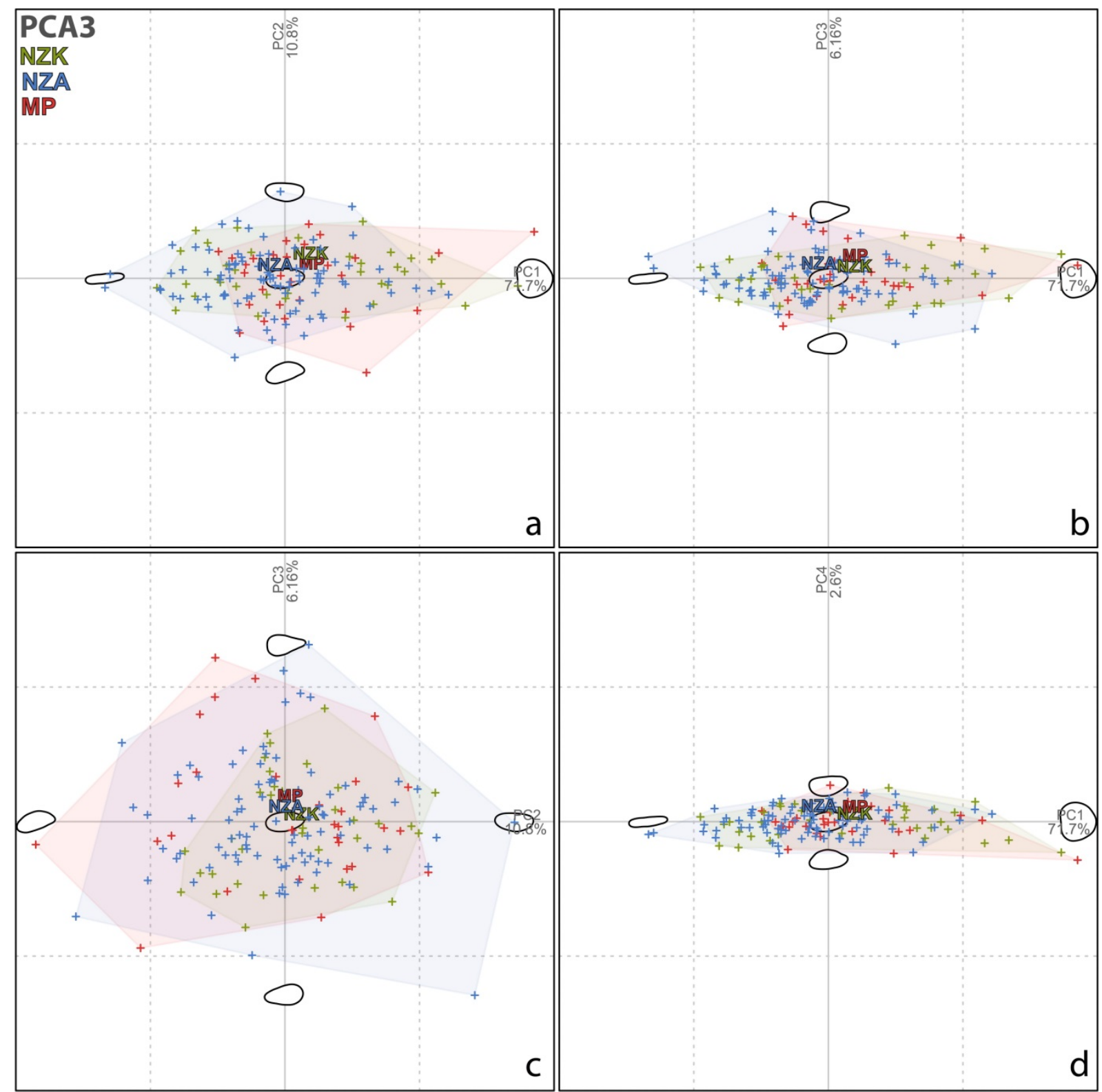

Figure 13. PCA3 - Plot of the PCA scores of the first four PCs. PCA is realised on EFA coefficients of the whole assemblages.

Using geometric morphometrics, we can observe that the variability seen in the upper faces of Lupemban points is encompassed within the variability of the whole assemblage to a greater degree than for the other analyses, although overall variability is lower and includes an important part of the elongated products (Figure 14). The PCA4 highlights that these products are more elongated (negative values of PC1), longitudinally symmetrical as indicated by their less extended distribution on the PC2 (Figure14a), and characterised by a general transversal symmetry as indicated by their less extended distribution on PC3 (Figure 14b, c). 


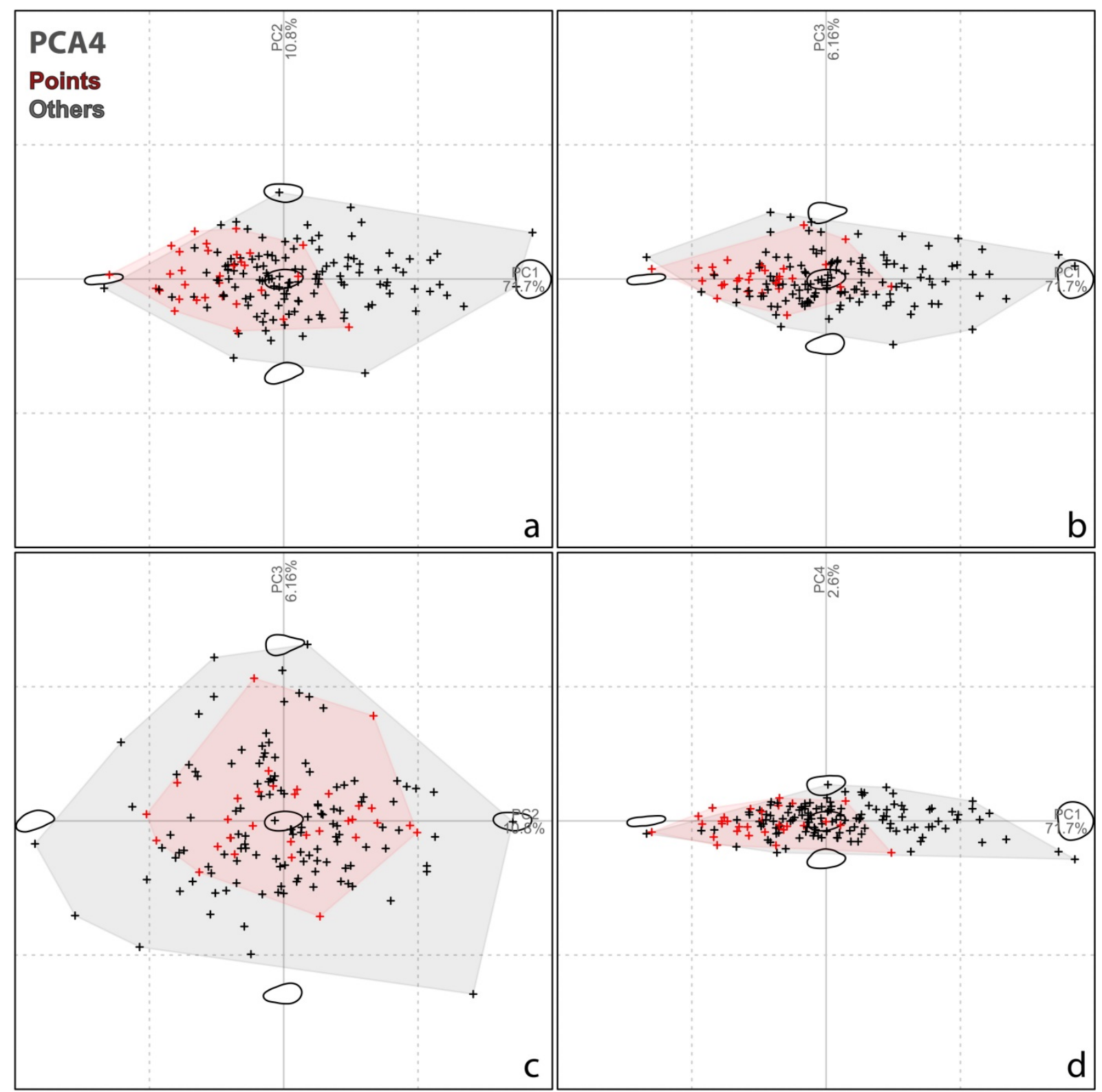

Figure 14. PCA4 - Plot of the PCA scores of the first four PCs. PCA is realised on EFA coefficients of the whole assemblages. Colours represent the categories: points are shown in red and the rest of the assemblage is in black.

When integrating the size of shaped tools in our analysis to confront it to the PCs scores obtained from EFA coefficients, MP differs from the other sites by possessing a more homogeneous size-range consisting of smaller products with a similar shape (Figure 15). The biggest piece from MP presents an important size difference with the biggest ones from NZK and NZA. We noted also that even if NZA and NZK largely overlap, the biggest pieces are found in NZA only. The PC1 versus the centroid size (Figure15a) clearly separates the Lupemban points from MP and those from NZA and NZK, both in size and in shape indicating important form differences. However, on the next PCs, the Lupemban points overlap on the x-axis (conformation of the PC2, 3 and 4) (Figure 15b, c, d).

Overall, these three approaches show similar results: a large variability of bifacially shaped tools within each site and an overlap of the three sites on the PCA plots. Only MP differs from the others with its lack of thin and elongated pieces. However, when comparing the artefacts identified as Lupemban points with the other bifacial tools in the assemblages, some differences arise both within (Figures 11b and 14) and between sites (Figure 15a). 

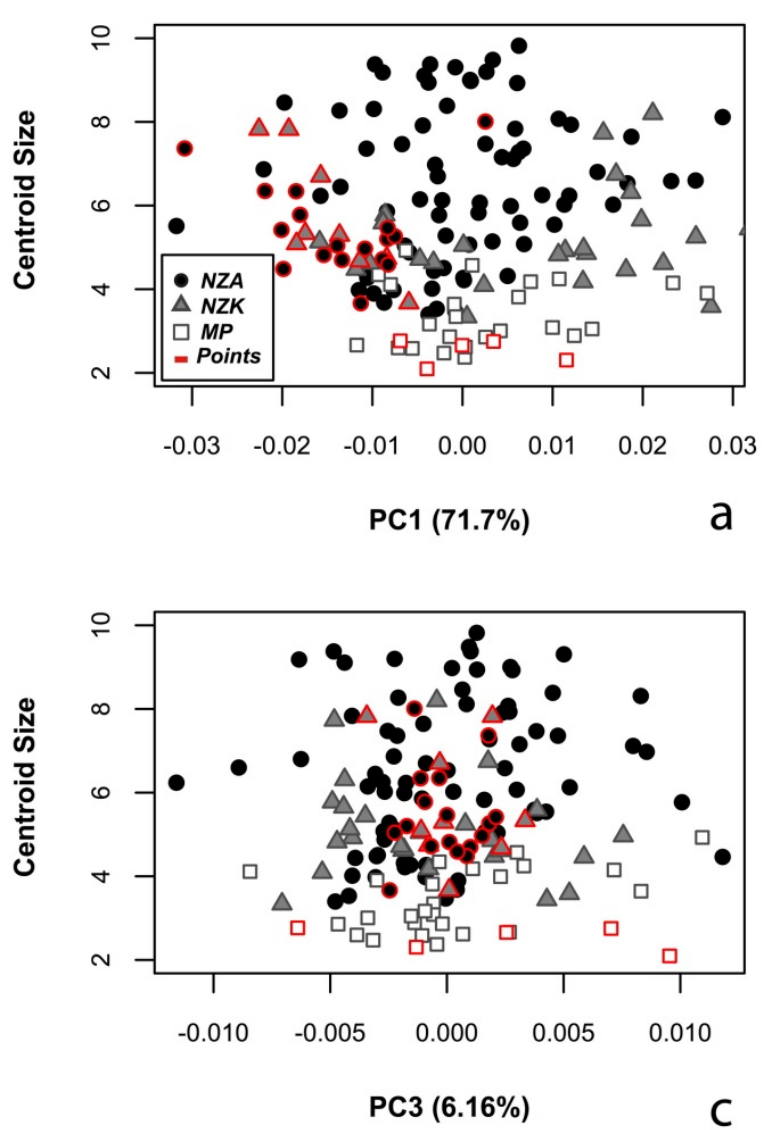
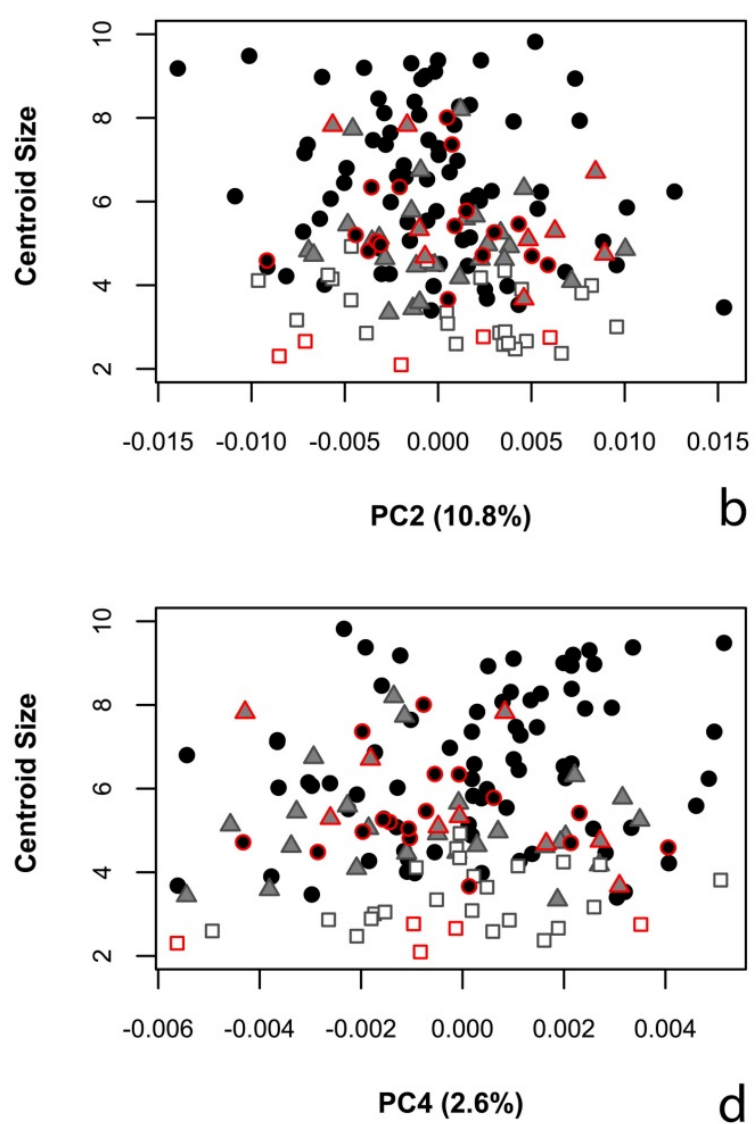

Figure 15. Bivariate plots of the first four PC scores (based on EFA coefficients) and the centroid size of the artefacts. Symbols represent sites (circles: NZA, triangles: NZK, squares: MP).

MANOVAs indicate that the LSR approach is the only one to present statistically significant results when testing PC1 scores versus sites (Table 7). However, the post-hoc Tukey HSD test indicates significant differences only between NZA and MP, and between NZA and NZK, but NZK and MP do not present significant differences between each other (Table 8). Testing PC2 scores versus sites, none of the pairs had a significant p-value. We applied the same test to centroid size versus sites and we obtained significant results for all pairs of sites (Table 8).

In traditional morphometrics, the Fineness index 1 has an important role in the distinction of points from their assemblage context (p-value: 9.419e-08). Although the profile characteristics were not among the criteria used to isolate Lupemban points from the other bifacially shaped tools, this indicates that Lupemban points have a thinner profile than other products and suggests the importance of profile thickness in analysing morphometric characteristics of these assemblages.

Results reported in Table 7 show that the section symmetry (symmetrical or asymmetrical) presents significant results. It may be due to the integration of profile measurements in this approach. We also tested whether raw material had an impact on our results but MANOVA resulted in non-significant p-values. It may be due to a similar treatment of raw materials or because NZA and NZK present the same raw materials as both sites come from the same valley which is rich in quartzite, sandstone and sandstone-quartzite outcrops. 
Table 7. MANOVA results realised on PC1-13 scores based on EFA coefficients, the five indices based on linear measurements and PC1-2 scores based on LSR variables for the whole assemblages. Significant values are in bold.

\begin{tabular}{lcccccc}
\hline & \multicolumn{2}{c}{ EFA } & \multicolumn{2}{c}{ Log Shape Ratio } & \multicolumn{2}{c}{ Five indices } \\
Qualitative sup. & Pillai & P-value & Pillai & P-value & Pillai & P-value \\
\hline Sites (NZA, NZK, MP) & 0.069586 & 0.0913 & 0.16618 & 0.001787 & 0.15824 & 0.05245 \\
Section type (symmetrical, & 0.037841 & 0.1155 & 0.027772 & 0.6352 & 0.070775 & 0.04906 \\
$\begin{array}{l}\text { asymmetrical) } \\
\text { Typology (points, other) }\end{array}$ & 0.19574 & $2.607 \mathrm{e}-07$ & 0.2314 & $8.78 \mathrm{e}-09$ & 0.28408 & $1.038 \mathrm{e}-09$ \\
$\begin{array}{l}\text { Raw material (quartzite, } \\
\text { sandstone, chert) }\end{array}$ & 0.16479 & 0.2147 & 0.19849 & 0.1498 & 0.3832 & 0.08478 \\
\hline
\end{tabular}

Table 8. Results of the post-hoc Tukey HSD tests conducted on PC1 and PC2 scores (LSR) and centroid size versus sites for the whole assemblages. Significant values are in bold. diff. : difference in the observed means, lwr : lower end point of the interval, upr : upper end point of the interval, p-value adj : p-value after adjustment for the multiple comparisons.

\begin{tabular}{lcccc}
\hline & Diff. & Lwr & Upr & p-value adj. \\
\hline PC1 scores (LSR) versus sites & & & & \\
NZK-MP & -0.2481461 & -1.001913 & 0.5056205 & 0.7164093 \\
NZA-MP & -1.0079970 & -1.644940 & -0.3710545 & 0.0007397 \\
NZA-NZK & -0.7598509 & -1.365108 & -0.1581942 & 0.0090958 \\
Centroid size versus sites & & & & \\
NZK-MP & 1.983190 & 1.0791083 & 2.887272 & 0.0000192 \\
NZA-MP & 3.081465 & 2.3175042 & 3.845426 & 0.0000000 \\
NZK-NZA & 1.098275 & 0.3766363 & 1.819914 & 0.0012326 \\
\hline
\end{tabular}

\subsection{Variability and diversity of Lupemban points}

When we isolate Lupemban points from the other bifacial points and conduct analyses again in the same way, we can observe more important distinctions between the sites, but these results need to be tested with a larger assemblage as only five pieces are considered in MP.

PCA5 is processed on the five indices and indicates a homogeneous stone point assemblage in MP whereas it is more variable in NZA and NZK (Figure 16). In the first PC (Figure 16a, b), as well as in the third one, MP points are mainly characterised by the more robust extremities than NZA where Lupemban points are characterised by a thinner section (fineness index 2) and a more elongated facial conformation (elongation index) (Table 9).

Table 9. Coordinates of the first four PCs and their $\cos ^{2}$ from the PCA5 presented in Figure 16. Variables with the highest contribution and quality of representation on the PCs are shown in bold.

\begin{tabular}{|c|c|c|c|c|c|c|c|c|}
\hline & $\begin{array}{l}\text { Cos. }^{2} \\
\text { PC1 }\end{array}$ & $\begin{array}{l}\text { Coord. } \\
\text { PC1 }\end{array}$ & $\begin{array}{l}\text { Cos. }^{2} \\
\text { PC2 }\end{array}$ & $\begin{array}{l}\text { Coord. } \\
\text { PC2 }\end{array}$ & $\begin{array}{l}\text { Cos. }^{2} \\
\text { PC3 }\end{array}$ & $\begin{array}{c}\text { Coord. } \\
\text { PC3 }\end{array}$ & $\begin{array}{l}\text { Cos. }^{2} \\
\text { PC4 }\end{array}$ & $\begin{array}{c}\text { Coord. } \\
\text { PC4 }\end{array}$ \\
\hline Fineness index 1 & 0.6454 & 0.8034 & 0.2199 & -0.4690 & 0.0473 & 0.2176 & 0.0861 & 0.2935 \\
\hline $\begin{array}{l}\text { Distal robustness } \\
\text { index }\end{array}$ & 0.5065 & -0.7117 & 0.0009 & -0.0310 & 0.4868 & 0.6977 & 0.0056 & -0.0749 \\
\hline $\begin{array}{l}\text { Proximal } \\
\text { robustness index }\end{array}$ & 0.6198 & -0.7873 & 0.1643 & 0.4054 & 0.0041 & -0.0642 & 0.2116 & 0.4604 \\
\hline Elongation & 0.3079 & 0.5549 & 0.6659 & 0.8160 & 0.0144 & 0.1202 & 0.0193 & 0.1390 \\
\hline Fineness index 2 & 0.8748 & 0.9353 & 0.0558 & 0.2362 & 0.0477 & 0.2185 & 0.0105 & -0.1029 \\
\hline
\end{tabular}




\section{PCA5}
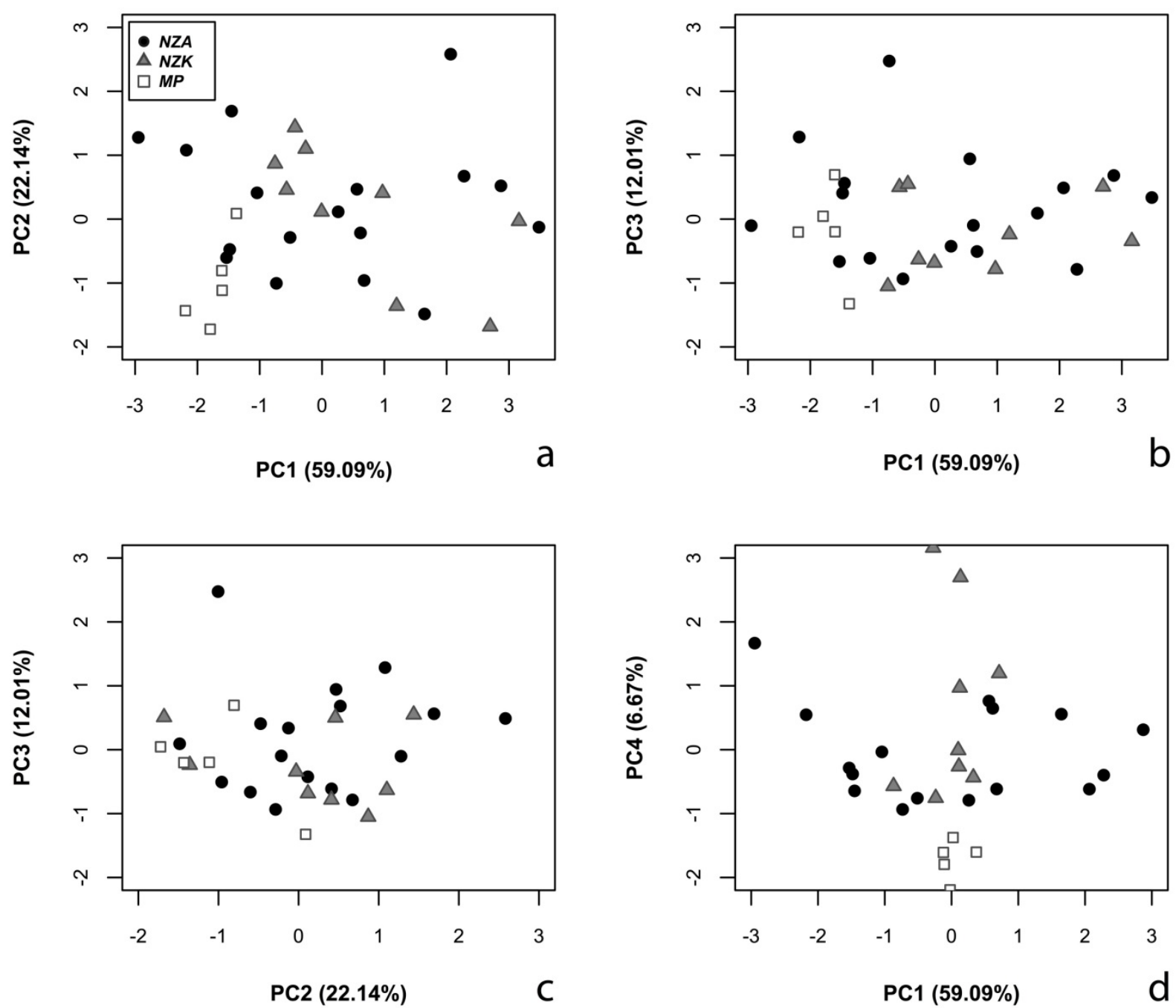

Figure 16. PCA5 - Plot of the PCA scores of the first four PCs. PCA is realised on the five indices listed in Table 1 and the results for this PCA are in Table 9 and concern only Lupemban points. Symbols represent sites (circles: NZA, triangles: NZK, squares: MP).

Performing PCA on LSR variables of Lupemban points, we notice that the first PC is strongly correlated with LSR-length and LSR-thickness whereas the second PC is mainly related to LSR-width (Table 10). Both PCs encompass $100 \%$ of variance (Figure 17). We observe that on both PCs, MP overlaps with NZA but not with NZK, whose products are thicker on the first PC. With the LSR, MP's Lupemban points seem less homogeneous than on the PCA5 processed on the five indices, but the superimposition of NZA and NZK on the plots is similar to the other methods.

Table 10. Coordinates of the two PCs and their $\cos ^{2}$ from the PCA6 presented in Figure 17. Variables with highest contribution and quality of representation on the PCs are shown in bold.

\begin{tabular}{lcccc}
\hline & Cos2 PC1 & Coord. PC1 & Cos2 PC2 & Coord. PC2 \\
\hline LSR-length & 0.9641 & -0.9819 & 0.0358 & -0.1892 \\
LSR-width & 0.0358 & 0.1892 & 0.9641 & 0.9819 \\
LSR-thickness & $\mathbf{0 . 8 3 4 4}$ & $\mathbf{0 . 9 1 3 5}$ & 0.1655 & -0.4068 \\
\hline
\end{tabular}




\section{PCA6}

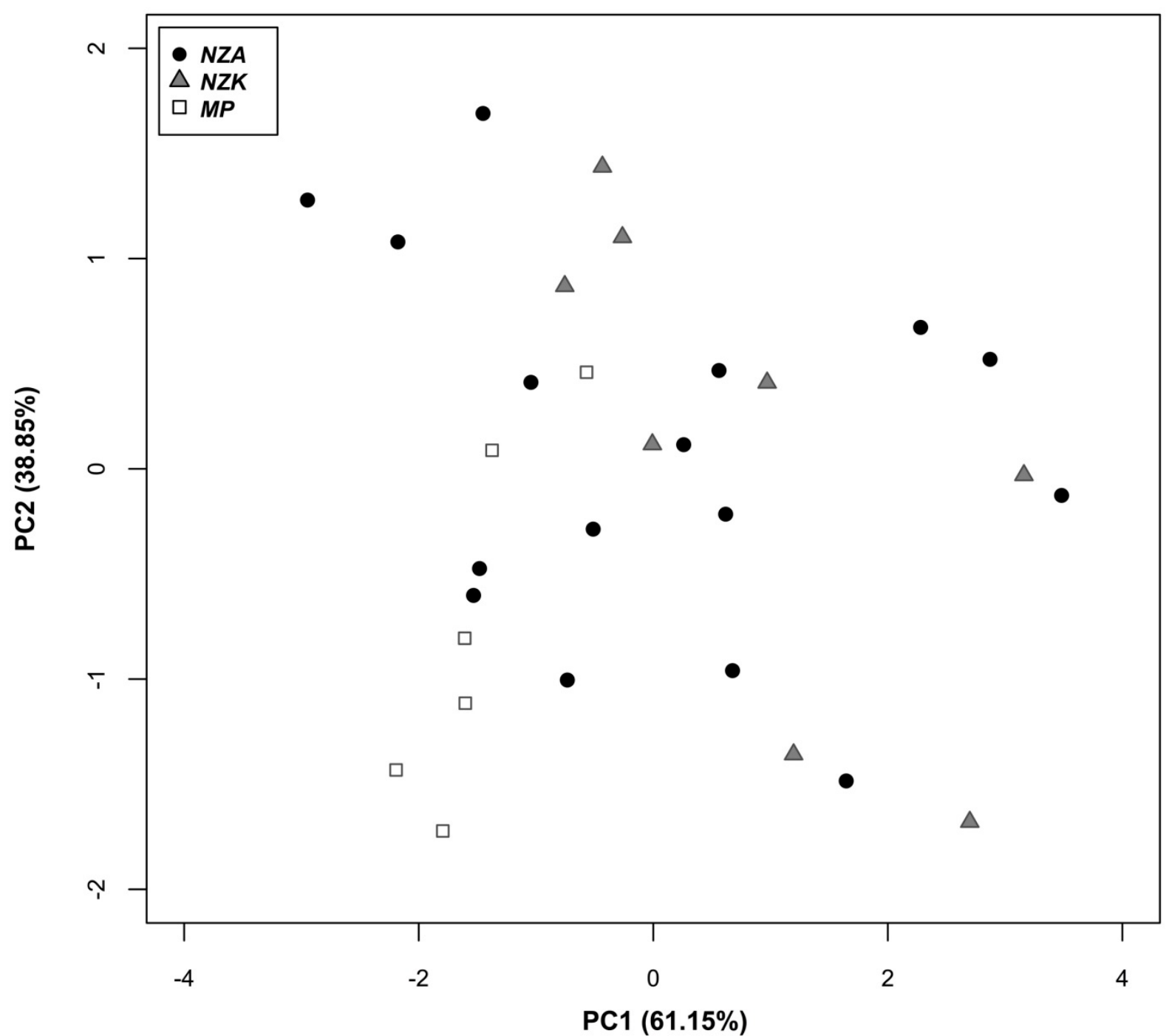

Figure 17. PCA6 - Plot of the PCA scores of the two PCs. PCA is realised on the three LSR variables. Results for this PCA are in Table 8 and concern only Lupemban points. Symbols represent sites (circles: NZA, triangles: NZK, squares: MP).

PCA performed on EFA coefficients of Lupemban points (Figure 18) shows nuances in the apparent homogeneity of MP's Lupemban points suggested by PCA5 performed on the five indices (Figure 16). On the PC1, we can observe an important distinction between MP and the two other sites (NZA and NZK) and this shows that MP points are also stockier (Figure 18a). Shape variability is as extended for MP as for NZK on the first PC and even more extended that for NZA on PC2, characterised by the longitudinal axis of symmetry, and on PC3, characterised by the transversal axis of symmetry. This suggests less symmetrical products at MP than at other sites. On the first PC, NZA's Lupemban points are more variable in elongation whereas NZK's points are more characterised by variability in the imbalance of the longitudinal axis of symmetry. On the other PCs, NZK and NZA are very close.

Again, the reintegration of centroid size shows important metric differences between MP, NZA and NZK. Plotting centroid size versus PC1 (Figure 19a), we observe that the longest pieces are the most elongated in NZK and NZA, with the exception of one piece. For centroid size versus PC3 and PC4 (Figure 19c, d), we observe that Lupemban points from MP were 
smaller with a homogeneous size range and a large variability in shape whereas the reverse is seen at NZA and NZK with large variability in size and a more homogeneous shape.

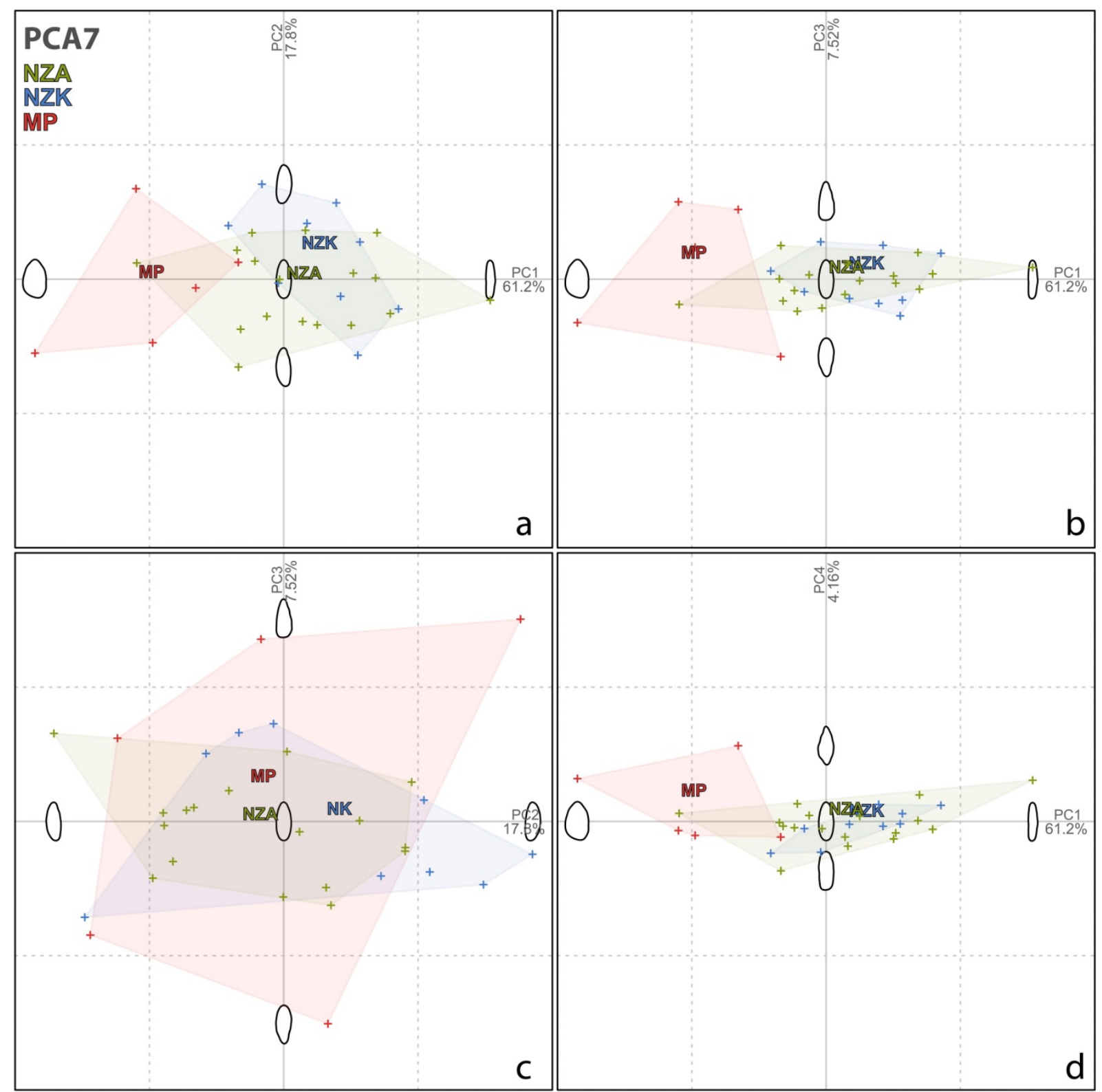

Figure 18. PCA7 - Plot of the PCA scores on the first four PCs. PCA is realised on the EFA coefficients. This PCA concerns Lupemban points only. Colors represent sites (green: NZA, blue: NZK, red: MP).

MANOVAs confirm these observations by highlighting significant differences between sites for the three approaches employed (Table 11). We performed MANOVAs on the PC scores based on the EFA coefficient (PC1-13) and the LSR (PC1-2), directly using the raw data of the five indices. We note that, again, testing the raw material we obtained $>0.05 \mathrm{p}-$ values with the same result for the section, indicating no link between raw material treatment, frontal symmetry (section type) and stone point shape in these studied assemblages (Table 11). 

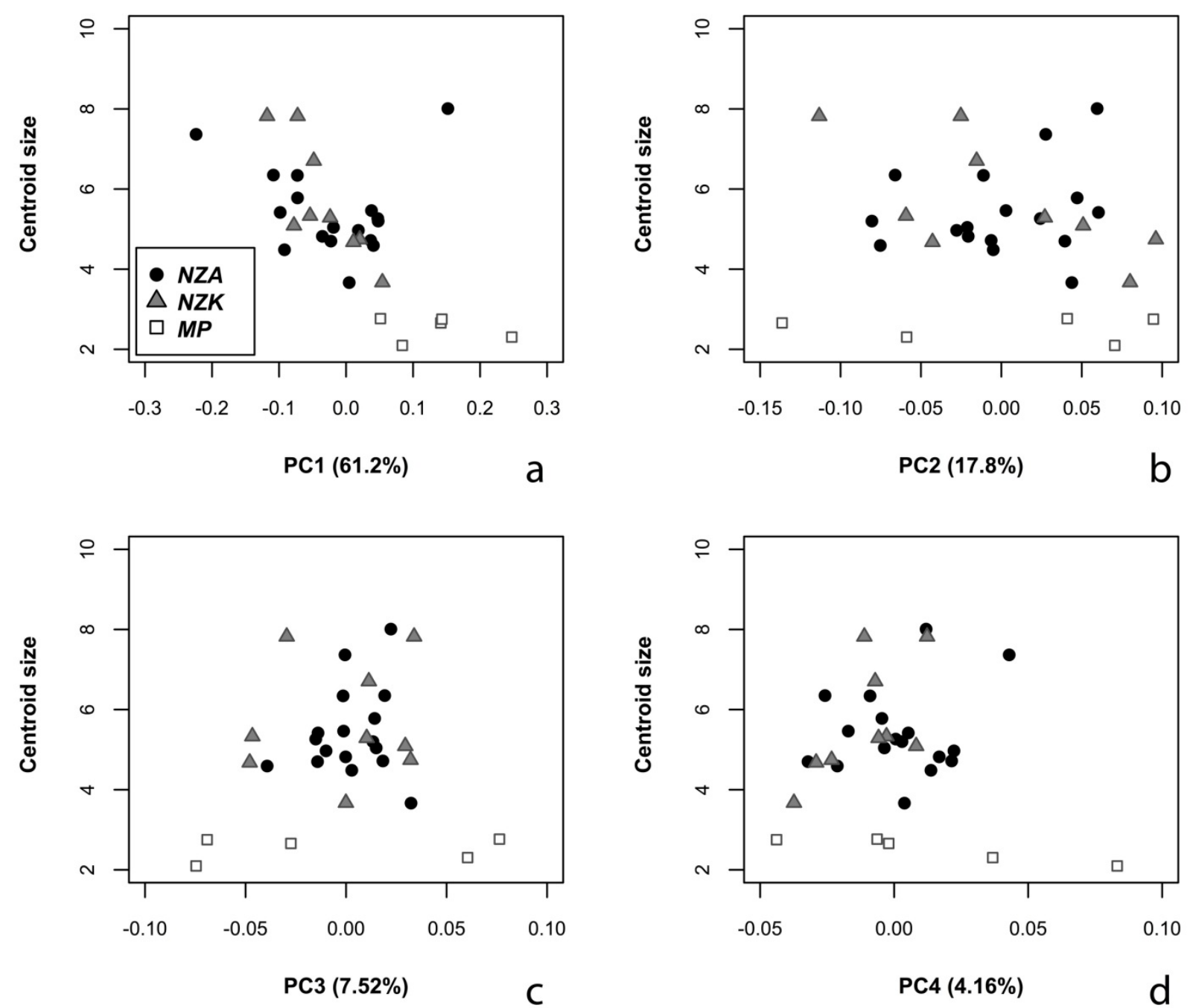

Figure 19. Bivariate plots of the first four PC scores (based on the EFA coefficients) and the centroid size of the Lupemban points. Symbols represent sites (circles: NZA, triangles: NZK, squares: MP).

Table 11. MANOVAs results for the Lupemban points assemblages, realised on EFA coefficient (PC1-13 scores), five indices, and LSR (PC1-2). Significant values are shown in bold.

\begin{tabular}{lcccccc}
\hline & \multicolumn{2}{c}{ EFA } & \multicolumn{2}{c}{ Log Shape Ratio } & \multicolumn{2}{c}{ 5 indices } \\
Qualitative sup. & Pillai & P-value & Pillai & P-value & Pillai & P-value \\
\hline Sites & 1.1891 & $\mathbf{0 . 0 3 7 6 2}$ & 0.38282 & 0.01659 & 0.48514 & 0.04376 \\
Section type & 0.46583 & 0.3928 & 0.04795 & 0.5026 & 0.85303 & 0.5256 \\
Raw material & 1.6474 & 0.6272 & 0.46377 & 0.07007 & 0.93149 & 0.09171 \\
\hline
\end{tabular}

The post-hoc Tukey HSD test was applied on the PC1 and PC2 scores versus sites (Table 12). It indicates that stone points from MP are different from the ones from NZA and NZK on the first PC but on the second, none of the sites present significant morphometric differences. This confirms the overlap of the three sites observed on the second component of the PCA6 (Figure 17). The test showed clear results for centroid size versus sites, indicating significant metric differences between MP and the other two sites, whereas the NZA and NZK have very similar size ranges. 
Table 12. Results of the post-hoc Tukey HSD test conducted on PC1-PC2 scores (LSR) and centroid size versus sites for the Lupemban point assemblages. Significant values are shown in bold. diff. : difference in the observed means, lwr : lower end point of the interval, upr : upper end point of the interval, p-value adj : p-value after adjustment for the multiple comparisons.

\begin{tabular}{|c|c|c|c|c|}
\hline & Diff. & Lwr & Upr & p-value adj. \\
\hline \multicolumn{5}{|c|}{ PC1 scores (LSR) versus sites } \\
\hline NZK-MP & 1.7686297 & 0.2984987 & 3.2387606 & 0.0158969 \\
\hline NZA-MP & 1.6233491 & 0.2824375 & 2.9642607 & 0.0151992 \\
\hline NZA-NZK & -0.1452805 & -1.2318043 & 0.9412432 & 0.941572 \\
\hline \multicolumn{5}{|c|}{ PC2 scores (LSR) versus sites } \\
\hline NZK-MP & 1.1376973 & -0.2010737 & 2.476482 & 0.1074766 \\
\hline NZA-MP & 0.8221847 & -0.3938145 & 2.0381838 & 0.2331168 \\
\hline NZA-NZK & -0.355126 & -1.3739040 & 0.7428788 & 0.7434548 \\
\hline \multicolumn{5}{|c|}{ Centroid size versus sites } \\
\hline NZK-MP & 3.1692434 & 1.6069488 & 4.731538 & 0.0000761 \\
\hline NZA-MP & 2.9064508 & 1.4814764 & 4.331425 & 0.0000707 \\
\hline NZK-NZA & 0.2627926 & -0.8918462 & 1.417431 & 0.8405946 \\
\hline
\end{tabular}

For the EFA coefficients, we used pairwise multivariate analysis of variance ("MANOVA PW" function of Momocs package (Bonhomme 2012; Bonhomme et al. 2014) which calculates MANOVA for every pairwise combination provided) and obtained similar results, namely the difference between MP and the other two sites (Table 13).

Table 13. Results of the pairwise multivariate analysis of variance realised on the PC1-13 (based on EFA coefficients) versus sites. Significant values are shown in bold.

\begin{tabular}{lll}
\hline & Pillai & p-value \\
\hline NZK-MP & 0.7309 & 0.03294 \\
NZA-MP & 0.4923 & 0.03804 \\
NZK-NZA & 0.1502 & 0.62501 \\
\hline
\end{tabular}

\section{Discussion and conclusions}

This paper provides an analysis of Lupemban bifacially shaped tools from "old" collections from Central Africa stored at the MNHN. It not only aimed to quantify the morphometric variability of the products of three assemblages, but also to test the morphometric coherence of the Lupemban points considered as a hallmark of the Central African MSA. To do so, we combined three different methods: two based on linear measurements (five indices based on seven measurements, LSR based on three measurements) and one based on 2D outlines (Elliptical Fourier Analysis (EFA)).

The five indices and the LSR allow us to document the proportions of pieces (from profile and top view). EFA provides detailed information of the outlines of the artefacts and thus allows us to examine irregularities in their shapes. Here, the outlines of pieces are also interesting because most of them are entirely shaped across their surfaces or have completely shaped margins. Thus, the outlines are integrally linked to the knappers' intended shape. The approaches we used are complementary. The five indices and the LSR show several differences in profile proportions between sites, whereas the EFA coefficients indicate considerable variability in shape. In addition, the integration of the centroid size gives us a complete view of the morphological and metric variation of the studied assemblages. We applied these methods to three assemblages from the Congo Basin (M'Piaka (MP), N'Zako 
Ambilo (NZA) and N'Zako Kono (NZK)) collected in the 1930s (MP) and the late 1960s (NZA, NZK). We have performed analyses on each assemblage to evaluate variability:

- within all bifacial shaped tools

- within Lupemban points only (as defined in the Introduction)

- between the Lupemban points and other bifacial tools

For each of these stages, we also compare the variability between sites.

When all bifacially shaped tools are considered, our analyses show important shape variability within each assemblage, in terms of elongation, robustness and symmetry. This variability is similar between sites as they are generally overlapping on all the PCAs conducted. The main differences identified were the absence of elongated products in MP's assemblage (see PCA1, 3, 5 and 7) and the presence of the most elongated and the biggest products in NZA's assemblage. MANOVAs conducted on the five indices and on PC scores based on EFA coefficients showed that there were no significant morphometric differences between sites. However, MANOVA and post-hoc Tukey HSD tests conducted on PC1 scores (59.97\% of variance) based on LSR indicated shape differences between NZA and the two other sites MP and NZK.

Important differences in the size of bifacially shaped tools between assemblages were noticed when observing the relationship between centroid size and shape. This suggests that these assemblages are mainly different in point sizes but present similar shape variability (Figure 20). These results echo the technological analysis (Mesfin 2018, Mesfin et al. in prep) which suggests significant diversity in the shaping chaîne opératoire among Lupemban assemblages. This size difference cannot be due to raw material nodule size as MP is located in an area well-known for its primary deposits of sandstone outcrops ('grès tendre') (Dadet 1966) which were exploited at several sites in the Pool Malebo area and which allowed some knappers to produce very large blanks and tools (Sangoan and Acheulean occupations). Since all bifacially shaped tools are also attributed to a close stage of reduction (Mesfin 2018), the difference in size is not due to different reduction stages. However, it may correspond to different functional needs of the final tool.

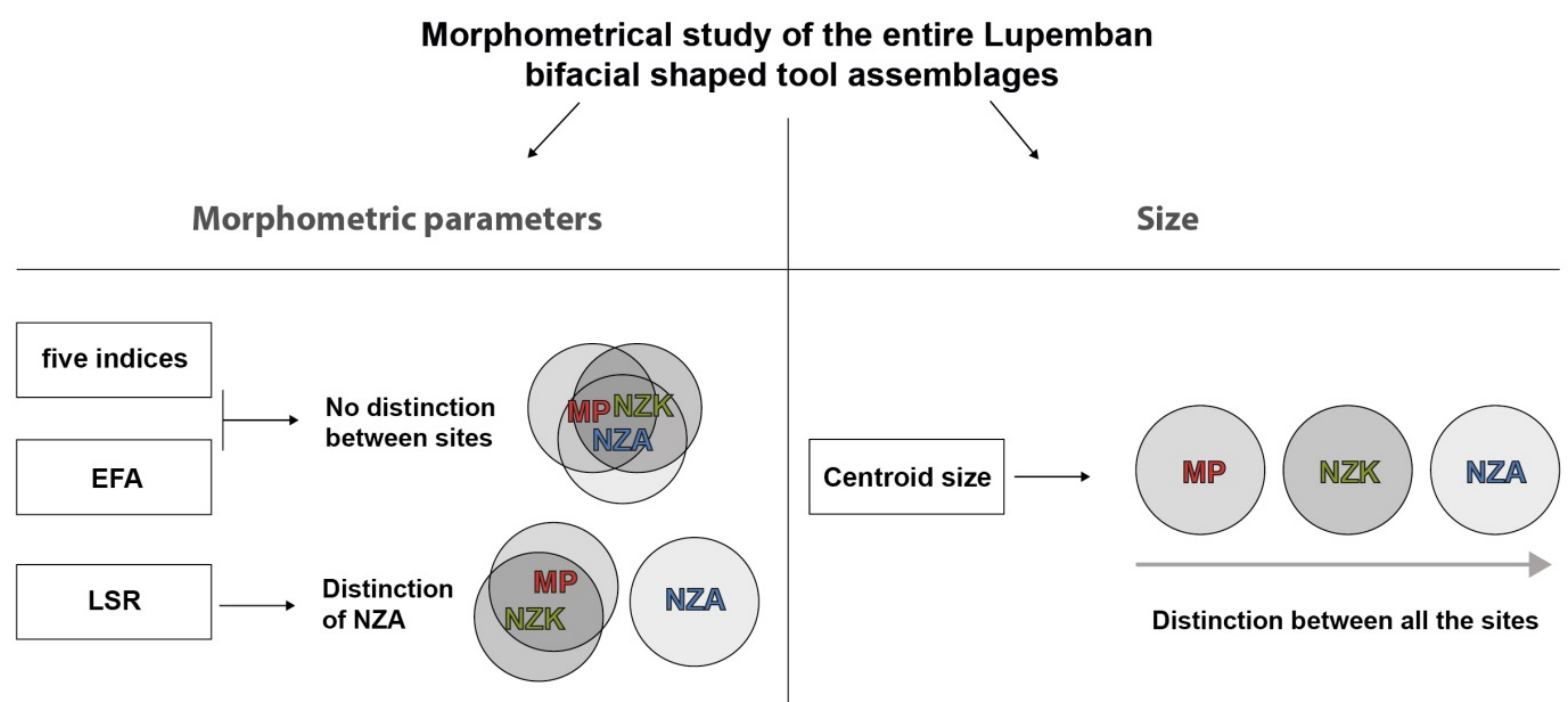

Figure 20. Summary of the results obtained with the different approaches (five indices, EFA, LSR) on the entire assemblages.

When looking at the distribution of Lupemban points compared to the other bifacially shaped tools, we observed significant morphometric differences using the three approaches: the Lupemban points are globally more elongated, thinner and more symmetrical. 
MANOVAs showed notable differences in morphology (shape and measurement indices) and size for each method employed. The fineness index 1 (length:maximal thickness) was important in differentiating Lupemban points from other products, indicating that bifacial points in these assemblages are characterised by a thinner profile. In future studies, a larger sample size could help to define a numerical interval for this fineness index to generate more precise Lupemban point criteria.

We then isolated the Lupemban points and applied an identical approach to assess whether assemblages differed from each other. We observed an important convergence of the three methods towards one main result, reinforced by MANOVAs and post-hoc Tukey HSD tests, showing significant morphometric differentiation between MP and the other two sites (NZA and NZK) (Figure 21). This highlighted the lack of homogeneity of the bifacial points. In particular MP points are smaller, less elongated and thicker. Despite the use of the lanceolate bifacial point as a Lupemban hallmark, we observed significant differences in shape and size between the three assemblages. Within the MP assemblage, Lupemban points presented very variable shapes, and for NZA and NZK, points show a large variability in size.

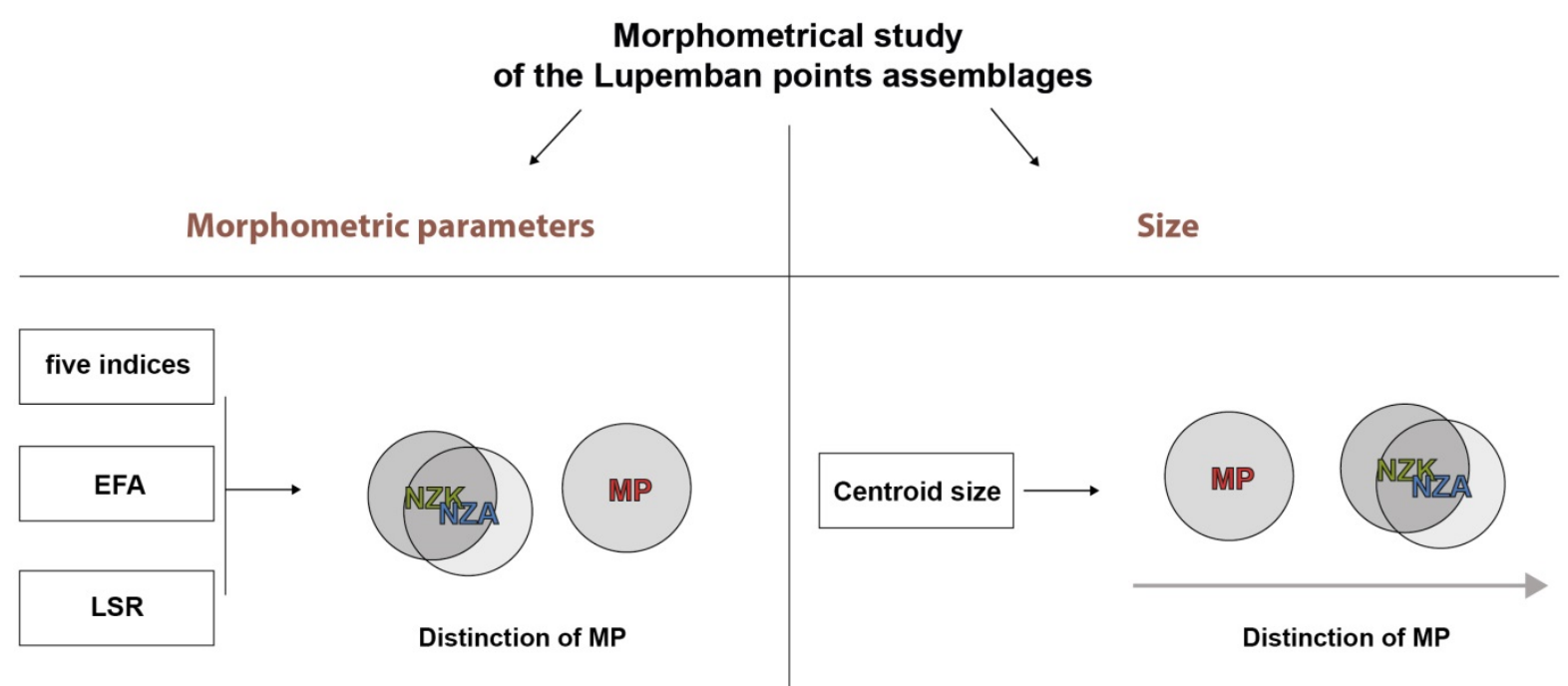

Figure 21. Summary of the results obtained with the different approaches for the Lupemban points.

Even though the chronological context of these assemblages is missing, these results may be compared at a larger scale to other MSA sites. There are few Lupemban assemblages with a controlled stratigraphic position and available age estimates; currently Kalambo Falls (Zambia), Sai Island (Sudan) and Muguruk (Kenya) appear to be the best documented, but none of them are located inside the Congo Basin. Published data from Muguruk (McBrearty 1985) offers the opportunity for a preliminary morphometric comparison using raw measurements of a random sample of 36 Sangoan-Lupemban bifacial shaped tools. This indicates similar morphological variability among all these sites (MP, NZA, NZK and Muguruk) (Figure $22 \mathrm{a}, \mathrm{b}$ ), and that "lanceolate points" (Lupemban points) from Muguruk (typological attribution made by McBrearty) also show substantial morphometrical variability and do not overlap with points from MP (Figure 22 c, d).

This preliminary comparison seems to reinforce our results but needs to be investigated further with additional samples. The results so far may suggest a great diversity of shaped tools within the MSA industries of Central Africa linked to cultural, chronological or functional patterns. This morphometric diversity may be expected in assemblages with uncertain contexts (such as "old" collections) but it also seems to be present in stratigraphically controlled assemblages. 
All bifacial shaped tools
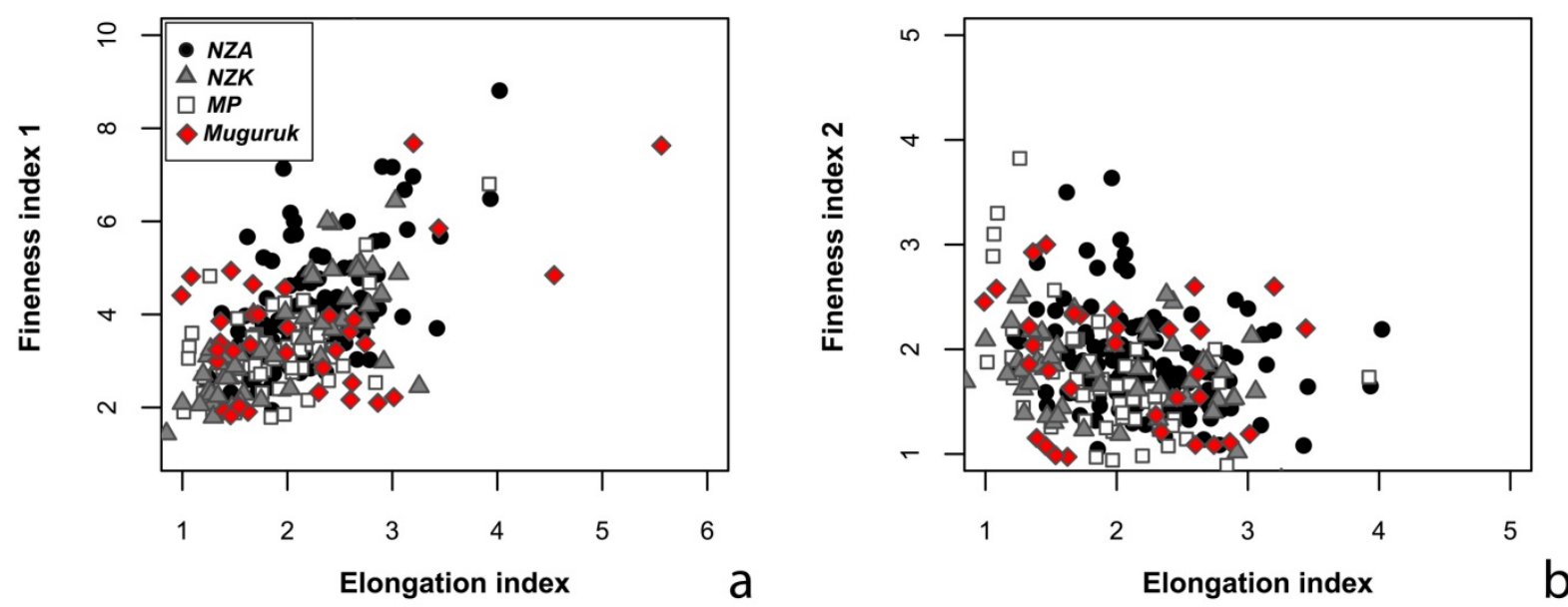

\section{Lupemban points only}
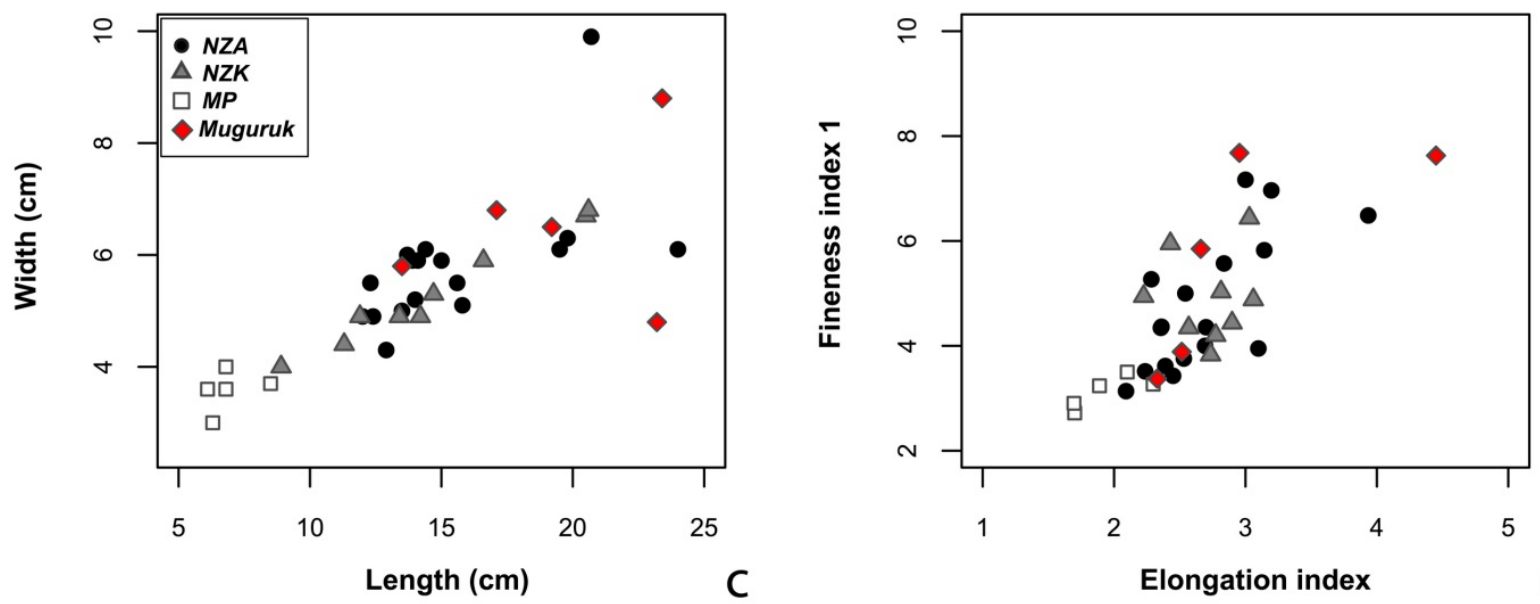

Figure 22. Bivariate plots of elongation index (a, b), fineness index 1 (a) and fineness index 2 (b) of entire studied assemblages and Muguruk published sample, and bivariate plots of width (c), length (c), fineness index 1 (d) and elongation index (d) of Lupemban points only from studied assemblages and Muguruk published sample. Symbols represent different sites (circles: NZA, triangles: NZK, squares: MP, diamonds: Muguruk).

Our results suggest that when using the current definition of "Lupemban points", these artefacts may not share similar patterns in different assemblages which raises questions about the typological and functional diversity of bifacial shaped points in Lupemban toolkit. The technological diversity of these products is also argued elsewhere (Mesfin 2018; Mesfin et al. in prep.). This lack of homogeneity between sites may also be due to a lack of chronological resolution among the Lupemban Complex (Lower or Upper Lupemban as used by J.D. Clark (1971; 2001)) and the observed variability may be explained by poor chronological resolution as assemblages may be in secondary deposits, or by too broad a definition of the "Lupemban point". The knapping skills of different tool-makers may also be another explanation for morphometric diversity across a single stone tool-type (Stout 2002).

If the observed morphometrical diversity is a consequence of too broad a definition of the "Lupemban point", the identification of other patterns such as technological patterns may help to better define Lupemban assemblages (Mesfin et al. in prep.). Under this scenario, variability and diversity among shaped tools may be more characteristic of Lupemban assemblages than the presence of typical pointed shaped tools. In the wider continental context of the African MSA, bifacial lanceolate points are present in several other regions such as in South Africa MSA (Porraz et al. 2008; Villa et al. 2009; Wurz 2002), or in 
Northern Africa (Scerri et al. 2016), but none share the diversity of shaped tools seen in Lupemban contexts.

To conclude, the results presented here underline the need to continue the reassessment of the Lupemban Complex in future studies. Assemblages from the Congo Basin margins (Kalambo Falls and Muguruk) and beyond (such as Peperkorrel in Namibia (MacCalman \& Viereck 1967) or Khor Abu Anga (Carlson 2015) and Sai Island in Sudan (Van Peer et al. 2003)) could help to elucidate whether Lupemban sites present similar morphometric patterns inside and outside of the equatorial Congolese Basin. In addition, the morphometric variability of bifacial shaped points must be appraised on a larger geographic scale, integrating other MSA shaped points. Further research should also focus on possible links between the MSA shaped tools from Central Africa and from Western Africa, as previously suggested by several authors (Davies 1964; 1976; Richard 1960), with recent studies identifying bifacial shaped points in the MSA industries of the West Africa (Chevrier et al. 2016; Scerri et al. 2016).

The combination of the three approaches employed (five indices and LSR based on linear measurements and EFA based on outlines) allowed us to quantify the morphometric diversity of Lupemban shaped tools and to evaluate the differences within the supposed Lupemban hallmark. These methods showed close results but also revealed some differences suggesting that several approaches are necessary to assess the morphometric variability of lithic assemblages. The two approaches based on traditional morphometrics highlighted the importance of the stone artefact profile morphometric data. They suggest that studying the 2D shape of superior face should be complemented by profile shape or using 3D models to obtain the third dimension of the pieces. However, even if morphometrics manage to quantify morphometric variability among these Lupemban assemblages, in the future, it is necessary to link this to functional and technological data to better interpret this variability.

The typologies established in past research using these collections lacked a precise definition for Lupemban artefacts, resulting in the creation of general regional hallmarks, such as the Lupemban point, which may have obscured more complex technological and cultural patterns in the Central African MSA. The present morphometric analyses explored the scientific potential of "old" collections and confirms the usefulness of reinvestigating old museum assemblages to develop our knowledge of the MSA, particularly in Central Africa where new fieldwork is rare.

\section{Acknowledgements}

We would like to thank the ANR Big Dry (ANR-14-CE31-0023) for supporting this research. AL's research is co-funded by ISA Bologna and by the Marie Curie Action, FP7, in the frame of the EURIAS Fellowship Programme. We are grateful to Henry de Lumley for authorising the study of assemblages from Central African Republic stored in the Institut de Paléontologie Humaine, and to Stéphanie Renault and Laurence Glémarec for helping our research in the prehistoric collections of the Muséum National d'Histoire Naturelle. We are also grateful to the organisers of the MetroArchaeo 2018 conference. We also thank Julie Arnaud and Marta Arzarello for their help and advice during this research. We thank two anonymous reviewers, whose comments have contributed to improving the paper, and Emily Hallinan for her help with the English editing of this manuscript.

\section{References}

Assoko Ndong, A. 2002, Synthèse des données archéologiques récentes sur le peuplement à l’Holocène de la réserve de faune de la Lopé, Gabon. L'Anthropologie, 106(1): 135-158. 
(in French) ("Review of recent archaeological data on the Holocene peopling of Lopé faunal reserve, Gabon") doi:10.1016/S0003-5521(02)01083-X

Babet, V. 1936, Note préliminaire sur un atelier de pierres taillées à Brazzaville (Afrique Equatoriale Française). Bulletin de la Société préhistorique de France, 33(2): 153-154. (in French) ("Preliminary note on a knapping workshop in Brazzaville (French Equatorial Africa") URL: http://www.jstor.org/stable/27912578

Barham, L. 2002, Backed tools in Middle Pleistocene central Africa and their evolutionary significance. Journal of Human Evolution, 43(5): 585-603. doi:10.1006/jhev.2002.0597

Barham, L.S. \& Smart, P.L. 1996, Current events: An early date for the Middle Stone Age of central Zambia. Journal of Human Evolution, 30(3): 287-290. doi:10.1006/jhev.1996.0023

de Bayle des Hermens, R. 1973, Recherches préhistoriques en République Centrafricaine. Ph.D. thesis at Muséum national d'Histoire naturelle, Aix-en-Provence, 500 p. (in French) ("Prehistoric research in Centrafrican Republic")

Bequaert, M. \& Mortelmans, G. 1955, Le Tshitolien dans le bassin du Congo. Vol. 5 Vol. 2. Académie Royale des Sciences Coloniales, Bruxelles, 40 p. (in French) ("The Tshitolian in the Congo Basin")

Bonhomme, V. 2012, A graphical introduction to Momocs and outline analysis using R. Retrieved November 26, 2019. URL: https://www.yumpu.com/s/p2HCjDt1C9jhOx8q

Bonhomme, V., Picq, S., Gaucherel, C. \& Claude, J. 2014, Momocs: Outline analysis using R. Journal of Statistical Software, 56(13): 1-24. doi:10.18637/jss.v056.i13

Bookstein, F.L. 1997, Landmark methods for forms without landmarks: morphometrics of group differences in outline shape. Medical Image Analysis, 1(3): 225-243. doi:10.1016/s1361-8415(97)85012-8

Borel, A. 2012, Formes et fonctions au sein des industries lithiques de la fin du Pléistocène et du début de l'Holocène en Asie du Sud-Est : un nouvel apport à la compréhension des comportements humains. BAR International Series Vol. 2351. Archaeopress, Oxford, 384 p. (in French) ("Stone tool forms and functions at the end of the Pleistocene and beginning of the Holocene in south-eastern Asia")

Borel, A., Cornette, R. \& Baylac, M. 2017, Stone Tool Forms and Functions: A Morphometric Analysis of Modern Humans' Stone Tools From Song Terus Cave (Java, Indonesia). Archaeometry, 59(3): 455-471. doi:10.1111/arcm.12264

Breuil, H. 1933, Pierres taillées venant du plateau de Mouka, Oubangui-Chari (Afrique Equatoriale Française). L'Anthropologie, 43: 222-223. (in French) ("Stone tools from the Mouka Plateau, Oubangui-Chari (French Equatorial Africa)")

Breuil, H. 1943, Le Paléolithique au Congo Belge d'après les recherches du Docteur Cabu. Transactions of the Royal Society of South Africa, 30(2): 143-160. (in French) ("The Palaeolithic of the Belgian Congo from Doctor Cabu's research") doi:10.1080/00359194309519836

Brooks, A.S., Yellen, J.E., Potts, R., Behrensmeyer, A.K., Deino, A.L., Leslie, D.E., Ambrose, S.H., Ferguson, J.R., d’Errico, F., Zipkin, A.M., Whittaker, S., Post, J., Veatch, E.G., Foecke, K. \& Clark, J.B. 2018, Long-distance stone transport and pigment use in the earliest Middle Stone Age. Science, 360(6384): 90-94. doi:10.1126/science.aao2646 
Brown, D.J., McSweeney, K. \& Helmke, P.A. 2004, Statistical, geochemical, and morphological analyses of stone line formation in Uganda. Geomorphology, 62(3-4): 217-237. doi:10.1016/j.geomorph.2004.03.002

Cardillo, M. 2010, Some Applications of Geometric Morphometrics to Archaeology. In: Morphometrics for Nonmorphometricians (Elewa, A.M.T., Ed.), Springer Berlin Heidelberg, Berlin, Heidelberg: p. 325-341. doi:10.1007/978-3-540-95853-6_15

Carlson, D.L. 2017, Quantitative Methods in Archaeology Using R. Cambridge University Press, Cambridge, 431 p. doi:10.1017/9781139628730

Carlson, R.L. 2015, Khor Abu Anga and Magendohli : Stone Age sites on the Sudanese Nile. BAR International Series Vol. 2768. BAR Publishing, Oxford, 145 p.

Chacón, M.G., Détroit, F., Coudenneau, A. \& Moncel, M.-H. 2016, Morphometric Assessment of Convergent Tool Technology and Function during the Early Middle Palaeolithic: The Case of Payre, France. PLoS One, 11(5): e0155316. doi:10.1371/journal.pone.0155316

Chevrier, B., Rasse, M., Lespez, L., Tribolo, C., Hajdas, I., Guardiola Fígols, M., Lebrun, B., Leplongeon, A., Camara, A. \& Huysecom, É. 2016, West African Palaeolithic history: New archaeological and chronostratigraphic data from the Falémé valley, eastern Senegal. Quaternary International, 408: 33-52. doi:10.1016/j.quaint.2015.11.060

Clark, J.D. 1967, Atlas of African prehistory. University of Chicago Press, Chicago, 38 maps and $62 \mathrm{p}$.

Clark, J.D. 1971, Problems of Archaeological Nomenclature and Definition in the Congo Basin. The South African Archaeological Bulletin, 26(101/102): 67-78. doi:10.2307/3888529

Clark, J.D. 2001, Kalambo Falls Prehistoric Site, III: The Earlier Cultures: Middle and Earlier Stone Age. Cambridge University Press, Cambridge, 701 p.

Clark, J.D., Beyene, Y., WoldeGabriel, G., Hart, W.K., Renne, P.R., Gilbert, H., Defleur, A., Suwa, G., Katoh, S., Ludwig, K.R., Boisserie, J.-R., Asfaw, B. \& White, T.D. 2003, Stratigraphic, chronological and behavioural contexts of Pleistocene Homo sapiens from Middle Awash, Ethiopia. Nature, 423(6941): 747-752. doi:10.1038/nature01670

Cornelissen, E. 2002, Human responses to changing environments in Central Africa between 40,000 and 12,000 BP. Journal of World Prehistory, 16(3): 197-235. doi:10.1023/a:1020949501304

Couttenier, M. 2012, Sociétés scientifiques, musées, universités. L’étude de la Préhistoire du Congo belge (1877-1936). Les nouvelles de l'archéologie, 128: 23-27. (in French) ("Scientific societies, museums, universities. The study of the Prehistory of Belgian Congo (1877-1936)") doi:10.4000/nda.1636

Dadet, P. 1966, Carte géologique de la République du Congo: zone comprise entre les parallèles $2^{\circ}$ et $5^{\circ}$ sud. Bureau de recherches géologiques et minières; Bureau minier de la France d'outre mer, Orléans. (in French) ("Geological map of the Republic of Congo: area between parallels $2^{\circ}$ and $5^{\circ}$ south")

Davies, O. 1964, The Quaternary in the coastlands of Guinea. University Press, Glasgow, $276 \mathrm{p}$.

Davies, O. 1976, The 'Sangoan' Industries. Annals of the Natal Museum, 22(3): 885-911. URL: https://hdl.handle.net/10520/AJA03040798_600 
Demayumba, N. 2018, Contribution à l'étude du Middle Stone Age (MSA) d'Afrique Centrale. Etude typo-technologique des industries lithiques des sites préhistoriques de MPila, Brazzaville, République du Congo. Master thesis at Muséum national d'Histoire naturelle, Paris, 80 p. (in French) ("Contribution to the study of the Central African Middle Stone Age (MSA). Typo-technological study of the lithic industries of the prehistoric sites of MPila Brazzaville, Republic of Congo")

Douze, K. 2011, L’Afrique de l'Est dans la réflexion globale sur le Middle Stone Age. Annales d'Ethiopie, 26(1): 15-51. (in French) ("East Africa in the global consideration on the Middle Stone Age") doi:10.3406/ethio.2011.1430

Droux, G. \& Bergeaud, G. 1937, Nouveaux ateliers préhistoriques à Brazzaville. Bulletin de la Société des Recherches Congolaises, 24: 210-233. (in French) ("New prehistoric workshops in Brazzaville")

Hublin, J.-J., Ben-Ncer, A., Bailey, S.E., Freidline, S.E., Neubauer, S., Skinner, M.M., Bergmann, I., Le Cabec, A., Benazzi, S. \& Harvati, K. 2017, New fossils from Jebel Irhoud, Morocco and the pan-African origin of Homo sapiens. Nature, 546(7657): 289292. doi:10.1038/nature22336

Husson, F., Josse, J., Le, S. \& Mazet, J. (2019). FactoMineR: Multivariate Exploratory Data Analysis and Data Mining (Version 2.0).

Ioviţă, R. 2009, Ontogenetic scaling and lithic systematics: method and application. Journal of Archaeological Science, 36(7): 1447-1457. doi:10.1016/j.jas.2009.02.008

Ioviţă, R. \& McPherron, S.P. 2011, The handaxe reloaded: A morphometric reassessment of Acheulian and Middle Paleolithic handaxes. Journal of Human Evolution, 61(1): 61-74. doi:10.1016/j.jhevol.2011.02.007

Kuman, K. \& Clarke, R.J. 2000, Stratigraphy, artefact industries and hominid associations for Sterkfontein, Member 5. Journal of Human Evolution, 38(6): 827-847. doi:10.1006/jhev.1999.0392

Lanfranchi, R. \& Lanfranchi-Salvi, C. 1986, Préhistoire du site de Brazzaville. In: Journée d'Etude sur Brazzaville, ORSTOM (Office de la recherche scientifique et technique outre-mer), Brazzaville, R. P. Congo: p. 57-74. (in French) ("Prehistory of the site of Brazzaville") URL: http://horizon.documentation.ird.fr/exldoc/pleins_textes/pleins_textes_7/carton01/25693.pdf

Lanfranchi-Salvi, C. 1990, Les industries du Stanley-Pool: problèmes stratigraphiques. In: Paysages quaternaires de l'Afrique centrale atlantique, Lanfranchi R., Schwartz D., Paris: p. 439-446. (in French) ("The Stanley-Pool industries: stratigraphic problems")

Lê, S., Josse, J. \& Husson, F. 2008, FactoMineR: An R package for multivariate analysis. Journal of Statistical Software, 25(1): 1-18. doi:10.18637/jss.v025.i01

Leakey, L.S.B. 1949, Tentative study of the pleistocene climatic changes and stone-age culture sequence in North-Eastern Angola. Publicações culturais Vol. 4. Companhia de Diamantes de Angola, Serviços Culturais, Lisboa, Portugal, 82 p.

MacCalman, H.R. \& Viereck, A. 1967, Peperkorrel, a Factory Site of Lupemban Affinities from Central South West Africa. The South African Archaeological Bulletin, 22(86): 41. doi:10.2307/3888081 
Matoumba, M. 2011, Recherches archéologiques dans la Nyanga (Sud-ouest du Gabon): 1929-2000. Editions Odette Maganga, Libreville, Gabon, 135 p. (in French)

("Archaeological research in Nyanga (south-western Gabon): 1929-2000")

Matoumba, M. 2013, Paléolithique au Gabon: les technologies lithiques dans la région de la Nyanga (sud-ouest). L'Harmattan, Paris, 192 p. (in French) ("Palaeolithic of Gabon: lithic technologies in the region of Nyanga (south-west)")

McBrearty, S. 1985, The archaeology of the Muguruk site, western Kenya. PhD thesis at University of Illinois Urbana-Champaign, CITY, 392 p.

McBrearty, S. 1988, The Sangoan-Lupemban and middle stone age sequence at the Muguruk site, western Kenya. World Archaeology, 19(3): 388-420. doi:10.1080/00438243.1988.9980048

McBrearty, S. \& Brooks, A.S. 2000, The revolution that wasn't: a new interpretation of the origin of modern human behavior. Journal of Human Evolution, 39(5): 453-563. doi:10.1006/jhev.2000.0435

Menghin, O. 1925, Die Tumbakultur am unteren Kongo und der westafrikanische Kulturkreis. Anthropos, 20(3/4): 516-557. (in German) ("The Tumba culture in the Lower Congo and the West African culture") URL: http://www.jstor.org/stable/40445048

Mercader, J. 2002, Under the canopy: the archaeology of tropical rain forests. Rutgers University Press, New Brunswick, 322 p.

Mercader, J., Martí, R., Martínez, J.L. \& Brooks, A. 2002, The nature of 'stone-lines' in the African quaternary record: archaeological resolution at the rainforest site of Mosumu, Equatorial Guinea. Quaternary International, 89(1): 71-96. doi:10.1016/S10406182(01)00082-9

Mesfin, I. 2018, Les assemblages lithiques lupembiens conservés au Muséum national d'Histoire naturelle : apports et perspectives pour la connaissance du Middle Stone Age d'Afrique centrale. Master thesis at Muséum national d'Histoire naturelle Erasmus Mundus, Paris, 127 p. (in French) ("The Lupemban lithic assemblages stored at the National Museum of natural History: contributions and perspectives for the knowledge of the Central African Middle Stone Age")

Mesfin, I., Leplongeon, A., Cabanès, J. \& Pleurdeau, D. in prep., New technological considerations on some Lupemban assemblages from the Congo Basin. unpublished manuscript in preparation.

Mosimann, J.E. 1970, Size allometry: Size and shape variables with characterizations of the lognormal and generalized gamma distributions. Journal of the American Statistical Association, 65(330): 930-945. doi:10.2307/2284599

O'Brien, T.P. 1939, The Prehistory of Uganda Protectorate. Cambridge University Press, Cambridge, $315 \mathrm{p}$.

Okumura, M. \& Araujo, A.G.M. 2018 (2019???), Archaeology, biology, and borrowing: A critical examination of Geometric Morphometrics in Archaeology. Journal of Archaeological Science, 101: 149-158. doi:10.1016/j.jas.2017.09.015

Pleurdeau, D. 2003, Le Middle Stone Age de la grotte du Porc-Épic (Dire Dawa, Éthiopie) : gestion des matières premières et comportements techniques. L'Anthropologie, 107(1): 15-48. (in French) ("The Middle Stone Age of Porc-Epic cave (Dire Dawa, Ethiopia): 
Raw material management and technical behaviours") doi:10.1016/S00035521(02)00003-1

Pommeret, Y. 1965, Civilisations préhistoriques au Gabon : Vallée du Moyen Ogooué, présentation de l'industrie lithique de tradition sangoenne, lupembienne et néolithique. Vol. 1 (Mémoire de la Société Préhistorique et Protohistorique Gabonaise ed.). Centre culturel français Saint Exupéry, Libreville, 65 p. (in French) ("Prehistoric civilisations of Gabon: Middle Ogooué Valley, presentation of the lithic industry of sangoan, lupemban and neolithic traditions")

Porraz, G., Texier, P.-J., Rigaud, J.-P., Parkington, J.E., Poggenpoel, C. \& Roberts, D.L. 2008, Preliminary characterization of a Middle Stone Age lithic assemblage preceding the 'classic' Howieson's Poort Complex at Diepkloof rock shelter, Western Cape Province, South Africa. South African Archaeological Society Goodwin Series, 10: 105121. URL: http://www.jstor.org/stable/40650022

R Core Team 2018, R: A Language and Environment for Statistical Computing. Vienna, Austria. Retrieved November 26, 2019. URL: http://www.R-project.org

Rezek, Z., Lin, S., Ioviţă, R. \& Dibble, H.L. 2011, The relative effects of core surface morphology on flake shape and other attributes. Journal of Archaeological Science, 38(6): 1346-1359. doi:10.1016/j.jas.2011.01.014

Richard, R. 1960, Hypothèses sur l'expansion et l'évolution des industries de Style Sangoen et Kalinien dans l'Ouest Africain. Bulletin de la Société préhistorique de France, 57(Fasc. 1/2): 95-104. (in French) ("Hypotheses on the expansion and evolution of the Sangoan and Kalinian industries in West Africa") doi:10.3406/bspf.1960.3437

Rohlf, F.J. 2015, The tps series of software. Hystrix, the Italian Journal of Mammalogy, 26(1): 9-12. doi:10.4404/hystrix-26.1-11264

Rohlf, F.J. (2018). tpsDIG2 (Version 2.31).

Scerri, E.M.L., Blinkhorn, J., Groucutt, H.S. \& Niang, K. 2016, The Middle Stone Age archaeology of the Senegal River Valley. Quaternary International, 408: 16-32. doi:10.1016/j.quaint.2015.09.025

Schwartz, D. 1996, Archéologie Préhistorique et processus de formation des stone-lines en Afrique Centrale (Congo-Brazzaville et zones periphériques). Geo-Eco-Trop, 20(1-4): 15-38. (in French) ("Prehistoric archaeology and formation processes of stone-lines in Central Africa") URL: http://horizon.documentation.ird.fr/exldoc/pleins_textes/pleins_textes_6/b_fdi_47-48/010011752.pdf

Serwatka, K. 2015, Shape variation of Middle Palaeolithic bifacial tools from southern Poland: a geometric morphometric approach to Keilmessergruppen handaxes and backed knives. Lithics - The Journal of the Lithic Studies Society, 35: 18-32.

Serwatka, K. \& Riede, F. 2016, 2D geometric morphometric analysis casts doubt on the validity of large tanged points as cultural markers in the European Final Palaeolithic. Journal of Archaeological Science: Reports, 9: 150-159. doi:10.1016/j.jasrep.2016.07.018

Stout, D. 2002, Skill and Cognition in Stone Tool Production: An Ethnographic Case Study from Irian Jaya. Current Anthropology, 43(5): 693-722. doi:10.1086/342638 
Taylor, N. 2009, The role of Lupemban core-axes in the hominin dispersal into the Congo basin, central Africa: a functional assessment by use-wear analysis. University of Liverpool. PhD thesis at University of Liverpool, Liverpool, 491 p.

Taylor, N. 2011, The origins of hunting \& gathering in the Congo basin: A perspective on the Middle Stone Age Lupemban industry. Before Farming, 2011(1): 1-20. doi:10.3828/bfarm.2011.1.6

Taylor, N. 2016, Across Rainforests and Woodlands: A Systematic Reappraisal of the Lupemban Middle Stone Age in Central Africa. In: Africa from MIS 6-2 (Jones, S.C. \& Stewart, B.A., Eds.), Springer Netherlands, Dordrecht: p. 273-299. doi:10.1007/97894-017-7520-5_15

Van Moorsel, H. 1968, Atlas de préhistoire de la plaine de Kinshasa. Université Lovanium, Kinshasa, 287 p. (in French) ("Atlas of Kinshasa plain prehistory")

Van Peer, P., Fullagar, R., Stokes, S., Bailey, R.M., Moeyersons, J., Steenhoudt, F., Geerts, A., Vanderbeken, T., De Dapper, M. \& Geus, F. 2003, The Early to Middle Stone Age Transition and the Emergence of Modern Human Behaviour at site 8-B-11, Sai Island, Sudan. Journal of Human Evolution, 45(2): 187-193. doi:10.1016/S00472484(03)00103-9

Van Peer, P., Rots, V. \& Vroomans, J.-M. 2004, A story of colourful diggers and grinders: The Sangoan and Lupemban at site 8-B-11, Sai Island, Northern Sudan. Before Farming, 2004(3): 1-28. doi:10.3828/bfarm.2004.3.1

Villa, P., Soressi, M., Henshilwood, C.S. \& Mourre, V. 2009, The Still Bay points of Blombos Cave (South Africa). Journal of Archaeological Science, 36(2): 441-460. doi:10.1016/j.jas.2008.09.028

White, T.D., Asfaw, B., DeGusta, D., Gilbert, H., Richards, G.D., Suwa, G. \& Howell, F.C. 2003, Pleistocene Homo sapiens from Middle Awash, Ethiopia. Nature, 423(6941): 742-747. doi:10.1038/nature01669

Wurz, S. 2002, Variability in the middle stone age lithic sequence, 115,000-60,000 years ago at Klasies river, South Africa. Journal of Archaeological Science, 29(9): 1001-1015. doi:10.1006/jasc.2001.0799 